\title{
Does random selection of selectors improve the quality of selected candidates? An investigation in the Italian academia
}

\author{
Daniele Checchi`, Silvia De Poli ${ }^{\star}$, Enrico Rettore
}

\begin{abstract}
We study a reform occurred in Italy in 2008 in the formation of selection committees for qualifying as university professor. Prior to the reform members of the selection committees were elected by their peers, whereas after the reform they have been randomly drawn. This policy was intended to increase the equality of opportunities of candidates via a reduction of the role played by connections to selectors. Results show that the reform was ineffective in reducing the probability contribution of being an insider, but attenuated the impact of being connected to a selector. The impact of scientific quality of candidates on the outcome of competitions is tiny both before and after the reform. We also find that candidates internalised the changed environment and adapted their strategy of application.
\end{abstract}

Keywords: University Recruitment, Incentives, Negotiation, Formal procedures

JEL classification: M51, I23, D82, J45

Acknowledgments: We thank Andrew Oswald for his kind comments, Nicolò Fraccaroli and Nicola Bazoli for research assistance in data collection. We also thank Giovanna Labartino for contributing in the initial stage of the project.

\footnotetext{
* FBK-IRVAPP, IZA, University of Milan, via Conservatorio 7, 20122 Milano, Italy.

- FBK-IRVAPP, IZA, University of Milan, via Conservatorio 7, 20122 Milano, Italy depoli@ irvapp.it, +39046131422 (corresponding author)

" FBK-Irvapp, IZA, University of Trento, Via Verdi 26, 38122 Trento, Italy
} 


\section{Does random selection of selectors improve the quality of selected candidates? An investigation in the Italian academia}

\section{Introduction}

The Italian academia is often described as plagued by cronyism and localism, which would be responsible for average poor performance as well as for the large degree of heterogeneity in research performance across university departments (Perotti, 2008, Durante et al. 2011, Moss 2012). This may explain why the formal rules of the hiring procedures have been repeatedly changed over the past decades, moving from national to local competitions in 1998 and back to a mixed system of national qualifications followed by local competitions in 2010. In the intermediate period, less radical changes were also introduced (reduction in the number of qualifications assigned through local competitions in 2003 and again in 2009). This paper focuses on one of these reforms, introduced in 2008, when competitions took place locally at department level: before the reform selection committees were elected by all academics in the field, while after the reform the composition of each committee was to a large extent randomly determined.

This reform was intended to reducing the advantage of local (often inbreeded) candidates, though the possibility of awarding up to a maximum of two qualifications per competition led very frequently to the assignment of one of them to a local applicant. By making the preordaining of competition outcomes less predictable, the reform also changed the behaviour of candidates, who were induced to expand the number of applications, though they had to withdraw a large fraction of them later on, given the existence of a maximum limit of five applications per year. Randomly selected committees may have dissimilar preferences about ranking candidates, and may be forced to rely more on objective measures of candidates' quality. Thus a second desirable outcome of the reform could have been the increased salience of scientific visibility (that we are going to proxy with the H index of the candidate) in the process of selection.

We take local competitions as our units of analysis, which we observe both before and after the reform. We obtain information on candidates and selectors from the final report compiled at the conclusion of each competition. Given the burden of work required for data collection, we limit ourselves to four large Italian universities observed over the 2003-2008 time window, covering 664 competitions in all disciplines. Despite the final report being typically silent about the internal discussion among selectors, we expect disagreement among randomly selected members being more frequent, and their influence in the process being possibly based on their own scientific visibility (also measured by their own $\mathrm{H}$ index).

Descriptive statistics suggest that candidates qualified after the reform have a higher scientific visibility than those obtaining the qualification before. One would be tempted to claim that randomized committees selected better candidates, but this is not necessarily the case. Random selection of selectors does not necessarily raises their average visibility (unless some access threshold is introduced, as occurred after 2010) and a fortiori their ability to select better candidates. What has clearly happened is a reduced role for previous connections, simply because the probability of matching candidates to a previously known selector declines (by construction). The reduction in information from pre-existing connections could have been compensated by stronger reliance on observable publication record, but the evidence on this is weak. We are unable to identify which channels were responsible for these mixed results: attraction of better candidates, more intense selfselection through withdrawal of applications, better selection of selectors, or a combination of them, due to lack of detailed information on the internal dynamics of the selection (which selector supported which candidate) and incomplete coverage of the process (we cover $11 \%$ of all competitions held in the country in the sample period). Thus we limit ourselves to pointing out that randomized committees are effective in diluting the effect of pre-existing connections, and speculate on other potential spillover effects.

The paper is organized as follows. The next section describes the institutional change introduced by the 2008 reform, and contrasts its peculiarity against an emerging literature on randomized selection 
committees. Section 3 illustrates our dataset and section 4 presents our results, including some robustness checks. Section 5 summarises the findings and section 6 concludes.

\section{The Italian recruitment of academics and the 2008 reform.}

The first decade of the 2000's has been characterised by a radical change in the selection of university professors in Italy. While in the 90's professors were selected in a national competition held every 4-5 years, in year 2000 competitions became local. ${ }^{1}$ Conditional on availability of funding allocated by the Senate of each university, each department in need of filling in a position opened a vacancy and formed a selection committee. The committee could assign up to three qualifications ("idoneità", then reduced to two in 2003, due to an unexpected - but foreseeable - "inflation" of qualifications), among whom the department chose the preferred candidate. The other qualified candidates could then be hired by other universities (for a more detailed description see also Moss 2012)

The transition from a nationwide competition (where the number of selected candidates coincided with the number of open positions) to local ones have been criticized as promoting nepotism in the academia as well as for being detrimental for the quality of the research. Durante et al. (2011) show that the transition to the local competitions has been accompanied by an increase of homonymy in some university departments, which they interpret as evidence of cronyism affecting the low social capital areas in the country. Allesina (2011) somehow complements their analysis, confirming the existence of a territorial divide between the North and the South of Italy in the extent of nepotism.

However, contrary to the expectations of previous authors, Checchi et al. (2014) do not find any significant impact of the reform on scientific productivity of Italian academics, irrespective of the outcome measure (number of papers, citations, cumulated impact factor). They suggest that the timing of competitions and the consolidated tradition of using objective measures of productivity in some research fields provided the relevant incentives, irrespective of how selections were undertaken.

These potentially contradictory results highlight the importance of focusing on committee formation, as one of the crucial dimensions of the hiring process. Under the national competition regime, selection committees resulted from a combination of elections (within each research field) and random draw. ${ }^{2}$ That system was considered excessively cumbersome and time consuming. As a matter of fact, it resulted in a relatively large amount of time devoted to fine tune strategic alliances among different wings in the same discipline, in order to minimize the risk of having a "winner takes all" outcome in the formation of the selection committee. For this reason, when moving to the local competition regime, the formation of selecting committees was substantially liberalized: each department opening a vacancy had the right to appoint one member (typically from the faculty), while the other four members were elected by the constituency represented by all professors in the field. ${ }^{3}$ However this setup often gave rise to draw-backs. Since being elected as committee member was not directly rewarded, university professors had a sort of "gift exchange" as the unique incentive to become

\footnotetext{
${ }^{1}$ The law (DPR n.390), approved in October 1998, became effective after the summer of 1999, so that the first promotions under the new rules took place around the end of 1999.

${ }^{2}$ Committees were composed by an odd number of members $(5,7$ or 9 , depending on the expected number of applications, which were clearly correlated with the size of the relevant research field). In the case of (national) competition for associate professorships, the committee was made of 2, 3 or 4 associate professors and 3, 4 or 5 full professors, all belonging to the same research field where the vacancy was called for. In the competition for full professorships, all members have to be full professors affiliated to an Italian university. In order to keep control of the discipline, the formation of selecting committees for full professorships were exposed to less uncertainty: the constituency of all full professors in a specific research field (among the existing 371) elected a triple number of potential members, and the Ministry randomly drew the actual committee. Vice versa, while forming selecting committees for associate professorships, the Ministry drew a threefold number of potential members from each relevant constituency, and each component (full and associated professors) elected their representatives in the selecting committee.

${ }^{3}$ While the size of the committee was fixed to five for all research fields, limitation in the number of candidates per competition was introduced by imposing a limit of a maximum number of applications equal to five per candidate each year. Candidate exceeding five applications were excluded by all competitions for that year.
} 
members of the selection committee. Academics accepted to become candidates in the electoral process leading to the committee formation in exchange of a promise of future reciprocation from colleagues in departments requesting their participation. While these incentives were appealing to prosocial attitudes, other "illicit" exchanges were also available: a professor appointed as internal member could invite other colleagues from other departments with the promise of assigning one qualification to their preferred candidates.

This mal-practice of preordaining the outcome of a competition before its start was clearly unfair to almost all participants in the competition, and was early lamented in press and in books (Perotti 2008). Different Ministries of Education tried to limit the incentives to malpractices, until the year 2010 when the system was again radically reformed, moving back to a national examination to obtain a qualification then followed by local competitions restricted to qualified candidates. ${ }^{4}$ One of these attempts prior to the 2010 reform - currently in operation - is the reform we examine in this paper: in 2008 the Ministry of Education issued an apparently marginal reform in the procedures of forming the selection committees. ${ }^{5}$

Replicating the selection principles once prevailing in national competitions, the constituency of academics in a research field was required to elect twelve potential members, among which the Ministry would have drawn four actual members. If the number of full professors in a given research field was lower than 12, all full professors were included in the pool, supplemented in case of need by professors of related disciplines, and fully random selection was then applied. ${ }^{6}$ The introduction of randomness in the formation of the committee was intended to preclude the possibility of preagreement, because the incentive of pre-assigning the qualifications was diluted among a large number of participants. In the sequel, we find clear evidence that this outcome has been attained, because the existence of connections between candidates and selectors loses impact on the probability of obtaining a qualification.

The decline in the probability of facing pre-existing connections between selectors and candidates attracted additional applications, from candidates who would have been otherwise discouraged. However, as the composition of the commission became revealed, some of these applications were withdrawn, due to the limit imposed on the maximum number (five) of applications per year.

In principle, pre-existing connections are not always detrimental, since they provide information about otherwise unknown candidates. With the decline in the probability of candidates-selectors connections, one would have expected other source of information becoming more relevant. Thus we would have expected scientific productivity and visibility, objectively inferred from the applicants' $\mathrm{CV}$, becoming more relevant among the selection criteria. However, different selectors may have different opinions about the importance of publishing papers in journals, often in relationship with the research field tradition and their own experience within it. Thus we are not surprised by the empirical analysis where the measure of scientific visibility (proxied by the $\mathrm{H}$ index of the candidates) has a very small impact on the probability of being selected and is statistical significant only in a subset of research fields (the so-called bibliometric sectors).

\footnotetext{
${ }_{5}^{4}$ See the law n.240/2010. For a description of the new system see Bagues et al. 2014.

${ }^{5}$ See the article n.1 of DL n.180 issued on 10/11/2008, n. 180 ("Disposizioni urgenti per il diritto allo studio, la valorizzazione del merito e la qualità del sistema universitario e della ricerca"), then converted into the law n.1/2009 dated 9/1/2009. The procedures were then specified by the Decreto Ministeriale n.139 dated 27/3/2009 ("Modalità di svolgimento delle elezioni per la costituzione delle commissioni giudicatrici di valutazione comparativa per il reclutamento dei professori e dei ricercatori universitari"). However, because of procedural delays, this reform was effective in changing the formation of selecting committees for all competitions opened in 2008 and concluded between 2009 and 2010.

${ }^{6}$ In 2008 there were 74 research fields (settori scientifico-disciplinari) out of 371 with a number of full professors less or equal to 13 , which therefore were exposed to pure randomization (since one professor has to serve as internal member and twelve represented the pool for selection). This however represents a lower bound, because each professor could serve as selector only once a year: thus two competitions in the same year and in the same research field would have required more than 26 professors in order to avoid pure randomization (and so on).
} 
These expectations are in line with the notion that random processes allow representativeness with respect to individuals and groups, thus ensuring greater equality of opportunity. Frey and Steiner (2014) report historical examples supporting this intuition, because randomness significantly reduces opportunities to influence political decisions by means of bribery and corruption. Random selection is often presented as an alternative to establishing quotas (by gender, age or race), and has the advantage of being cost minimising, since it makes lobbying activities ineffective. More recently, selective randomness (i.e. random selection from among a pool of pre-chosen and qualified candidates) has been proposed as a compromise between equity and efficiencies (Goodhall and Osterloh 2015). While preserving equality of opportunity (i.e. all individuals have the same ex-ante probability of being selected) it avoids the psychological cost of non-winning and therefore may attract members of minorities who otherwise would self-select out of the competition.

In the literature on academic competitions random selection of examiners has not been considered for its equity or efficiency properties, rather is has typically exploited to support a causal interpretation of the correlation between observable characteristics of selectors and outcomes of selections. In a paper exploiting the same reform we focus on here, De Paola and Scoppa (2015) study the impact of selectors' gender on the probability of appointment to professorship of female candidates. Their sample consists of 130 competitions held in two research fields (economics and chemistry) in the aftermath of the reform (vacancies opened in 2008). They provide robust evidence that gender composition of selection committees matters, and that female selectors reduce gender discrimination experienced by female candidates.

Zinovyeva and Bagues (2015) exploit random matching of candidates to evaluators to measure the (causal) effect of pre-existing connections on the probability of being qualified as professors in Spain during the period 2002-2006. Due to the lack of rules on conflict of interests it happened that candidates were evaluated by professors who have been their $\mathrm{PhD}$ supervisors, or co-authors, or even colleagues; they find that candidates are 50 percent more likely to be promoted when the committee includes selectors who are strongly connected to them. They consider the positive contribution of connections as source of information, distinguishing between good and bad view of networks; however their conclusion is that biased assessments prevail, identified by looking at scientific productivity in the subsequent five years after selection. ${ }^{7}$

Random matching of selectors and candidates is also exploited in the analysis of the recently introduced qualification round for Italy (Bagues et al. 2015 and 2017). In the second paper the authors find that having a woman in the examining committees is detrimental to the chance of female candidates to be promoted, ${ }^{8}$ concluding that the introduction of gender quotas in evaluation committees might have unintended consequences. In the first paper they examine the role of connections (colleagues and/or co-authors) in the probability of withdrawing from competitions, showing that weak candidates are more likely to withdraw their applications once a connected examiner is randomly drawn. Differently from Zinovyeva and Bagues (2015), they argue that selfselection of applicants due to application withdrawals is consistent both with a pro-bias and with a pro-information interpretation of the role of academic connections. ${ }^{9}$ This self-selection is also

\footnotetext{
${ }^{7}$ Similar approach is contained in Godechot (2016): shortlists for faculty recruitment at one leading French university (the École des Hautes Études en Sciences Sociales - EHESS) between 1960 and 2005 were compiled by a randomly selected committee made of department members. Thanks to information on $\mathrm{PhD}$ supervisorships, the author is able to measure the gain in probability experienced by a candidate whose supervisor was randomly selected against an otherwise identical candidate whose supervisor was not selected.

8 "Each additional female evaluator decreases by two percentage points the success rate of female applicants, relative to male applicants" (Bagues et al. 2017, p.5)

9 "Researchers in the top tercile in terms of their research output are 5 p.p. more likely to succeed when the committee includes a co-author or a colleague. Weaker researchers also benefit from connections by not making costly errors in application decisions. Researchers in the bottom tercile are 6 p.p. less likely to apply when the evaluation committee includes a co-author or a colleague and their chances of success are 3 p.p. higher. As a result, the probability that they fail the evaluation is 9 p.p. lower. Evidence from a subsequent round of evaluations suggests that, by postponing their application, weak researchers with a connection in the committee benefit also from higher success rates in the future. Overall, the evidence is consistent with the existence of a
} 
gendered, as shown by DePaola et al. (2014), where they consider as potential applicants all assistant or associate professors in the Italian academia, and they show that the gender gap in the probability of applying for a competition holds true only for individuals in the lower tail of the distribution of scientific productivity.

With respect to previous literature, we take a different perspective, since we analyse the impact of introducing randomisation in the commission formation onto the probability of appointment of insiders. Randomisation was intended to increase equality of opportunities among candidates, against the bad habit of nepotism and/or simply inbreeding. We show that this outcome was achieved via reduction of the impact of connections between candidates and selectors (here measured by common departmental affiliation). However, previous literature stresses the double-face nature of connections, because they may bias evaluators' judgments, but they may also reduce informational asymmetries about otherwise unknown candidates. As a consequence, we would have expected an increase in the explanatory power of observables (like scientific productivity), which is not always observed in the data. The competition outcome is analysed as a two-stage procedure, for candidates had the possibility of withdrawing their applications before the selection process starts. Since we do not cover all competitions taking place during our sample period, we cannot investigate the drivers of candidate applications, and therefore we cannot assess the actual degree of self-selection of candidates. Still, we do observe how they react as the information on the composition of the recruiting committee become publicly available.

\section{Our dataset}

We use data from different sources. We collected data from the final report (verbale riassuntivo) produced by each selecting committee in competitions for associate and full professor positions opened in four large Italian universities - Padua, Milan 'Statale', Naples 'Federico II' and Rome 'La Sapienza' - from 2003 to $2008 .{ }^{10}$ For each competition, we have information about the recruiting committee, the pool of applicants, the candidates that withdrew from the competition before its conclusion (including those who did not show up for the interview) and the winners. ${ }^{11}$

The competitions included in our sample qualify (up to) two candidates, among which the local department chooses the one to be appointed. The department can also refuse to hire anyone in case they do not like the qualified candidates. In this case the department cannot open a new vacancy for the same position over the subsequent 12 months. The qualified candidate(s) not recruited by the department opening the position can be hired by any other department willing to create a new post. ${ }^{12}$

bias in favour of connected candidates and also with the notion that connections reduce information asymmetries." (Bagues et al. 2015).

${ }^{10}$ By the end of the sample period (31/12/2008), these universities accounted for almost $20 \%$ of the whole Italian academia: their faculties (including tenured full, associate and assistant professors) were 2427 (Milan $1^{\text {st }}$ university, known as Statale), 2382 (Padua), 3017 (Naples $1^{\text {st }}$ university, known as Federico II) and 4704 (Rome $1^{\text {st }}$ university, known as La Sapienza), against an overall population of 63290 academics. In terms of quality, the most recent research assessment exercise (VQR 2004-2010 - table 6.10a of the final report) ranked the Italian top five universities in the following order: Bologna, Rome, Padua, Milan and Naples.

${ }^{11}$ In some research field it is a common (still undocumented) practice to let the candidates know they have limited chance to be selected in a specific competition. Given the limit of five applications per year, one possible (and intended) outcome of this communication is the withdrawal of the application from the specific competition.

12 There is an apparent cost differential between hiring an internal or an external candidate. Taking the cost of a full professor as a reference (in the Italian academic jargon this corresponds to 1 punto organico), the cost of an associate professor is conventionally set at 0.7 points and a cost of an assistant professor set to 0.5 points. Thus promoting an internal associate professor to full professor would apparently cost only 0.3 points to the department making the hiring, whereas hiring an external (qualified) candidate for the same position would cost 1 point. However this cost differential is only apparent, since in the former case a department would gain a full professor while losing an associate professorship, thus implying an overall cost of 1 point $(0.3$ for internal promotion +0.7 for the disappearance of an associate position), This is cost equivalent to the latter alternative of hiring a full professor from external candidates. 
Candidates were allowed to apply to a maximum of five competitions per year both before and after the reform. Anecdotal evidence suggests that some candidates strategically applied to more than five competitions per year, withdrawing excess applications once the composition of the selecting committees became publicly known. However this has to be considered as a risky strategy because if the withdrawal of the application was received after the first meeting of the committee, the candidate was excluded from all competitions s/he has applied for. An alternative interpretation applying to the pre-reform competitions is that once the committee was formed and a shortlist of candidates was informally agreed upon (even before the first meeting), some selector may have actively pressed outof-list candidates to withdraw from the competition, under the threat of a negative judgment in the official report. ${ }^{13}$

\subsection{Candidates and members of selecting committees}

For each candidate and member of committees we have information about age, gender, the university of affiliation at the time of competition and their research record. Age is obtained from administrative archives for tenured academics or searching on-line their CVs otherwise. ${ }^{14}$ The affiliation of candidates and evaluators are obtained by open data sources of the Italian Ministry of Education and University ${ }^{15}$.

The research record is obtained from two alternative data sources, Publish or Perish (PoP), which is based on Google Scholar, and Scopus (www.scopus.com), promoted by Elsevier. The advantage in using Scopus is the reduction in the risk of homonymous confounders, since each author can be identified with affiliation and research field. On the other hand, Scopus does not properly cover humanities, where scholars often write in Italian; in this case, we use PoP to collect data for these fields of study.

For each applicant and selector, we have collected the number of papers, the number of citations and the $\mathrm{H}$ index ${ }^{16}$. Note that this information on the research standing of candidates and selectors are referenced to the date we downloaded them from the web (from March to December 2014) because it would have been an excessive workload to retrieve this information referred to the time when competitions took place, especially for the PoP database. However, to understand whether this approximation may bias our analysis, we collected the research standing for a small subsample of candidates over the period 2003-2014. The comparison between the $\mathrm{H}$ index as of the date of extraction and the corresponding measure at the time of the competition suggest that we do not introduce systematic measurement errors in the analysis by allowing such an approximation. ${ }^{17}$

Since the features of the distribution of the number of publications and of the $\mathrm{H}$ index vary significantly across fields of study, we standardise them using the field specific averages and standard deviations as computed on candidates included in our sample who applied before the reform. ${ }^{18}$ Candidates who applied after the reform are not included in this calculation to avoid a potential bias that could have been created by the reform itself.

\subsection{Competitions}

\footnotetext{
${ }^{13}$ Bagues et al. (2015) obtain similar results for national qualification exams, and they interpret it as evidence of information provision associated to academic ties.

${ }^{14}$ Whenever we do not find the date of birth we use the year of graduation to estimate the age; when this is absent, missing values are replaced them with the average age of candidates in the field of study.

${ }_{16} \mathrm{http}: / /$ cercauniversita.cineca.it/php5/docenti/cerca.php

${ }^{16}$ An $\mathrm{H}$ index equal to $n$ means that the researcher has published at least $n$ papers cited by at least $n$ other publications.

${ }^{17}$ This analysis is discussed in section A2 of the Appendix.

${ }^{18}$ In section A3 of the Appendix we report the number of observations, the mean and the standard deviation used for this standardisation (see tables A3 and A4).
} 
We consider 664 competitions included in the sample, 230 to full professorships and 434 to associate professor positions ${ }^{19}$. Table 1 shows the average number of candidates and the fraction of withdrawals in competitions before and after the reform. Descriptive statistics are presented separately for two wide research areas: the bibliometric disciplines (where the prevailing pattern of research assessment is based on bibliometric indices), including mathematics and informatics, physics, chemistry, earth sciences, biology, medicine, agricultural and veterinary sciences, engineering, psychology; the nonbibliometric disciplines, gathering humanities, literature, history, philosophy, art history, pedagogy, law studies, economics and statistics, political and social sciences, architecture. Table 1 shows that prima facie the reform resulted in a large increase of the average number of candidates per competition. This is likely due to the increased uncertainty about the committee composition to which potential candidates reacted by submitting a larger number of applications. ${ }^{20}$

The percentage of withdrawals is higher in competitions for associate professorships (in the order of half of the applicants) since participation costs are higher: when shortlisted, the candidate has to be personally interviewed at the university opening the position. ${ }^{21}$

Table 1 about here

\subsection{Selecting committees and candidates}

Table 2 provides some descriptive statistics on selecting committees. After the reform more than half of committees included at least one woman, while before the reform this percentage was significantly lower (40.6\%), at least for competitions for full professorship. The before-after comparison of the $\mathrm{H}$ index of the selectors is not straightforward to interpret, since the difference between the $\mathrm{H}$ index collected in 2014 and the $\mathrm{H}$ index collected at the time of the competition increases over time (see again section A2 in the Appendix). At face value, statistics reported in table 2 suggest that the reform increased the average research quality of evaluators as well as their variability in competitions for associate professorships. ${ }^{22}$ Also note that the $\mathrm{H}$ index of the internal selector appointed by the departments slightly increased. As a possible reaction to the reform, departments started to appoint internal examiners with a better research record. The overall effect is an increase in the quality of the selecting committees.

The random selection of external members should have prevented possible pre-agreements between the internal member and the supposed-to-be-elected selectors, thus reducing the "similarity" among them. If we take the correlation index between their $\mathrm{H}$ indices as a proxy for such a similarity, we observe a decline in the case of competitions for associate professorships (which is remarkable when considering the replacement of associate professor members with full professor ones), not in the case of full professorships.

\section{Table 2 about here}

Another effect of the reform is the moderate increase of the average distance between the university of affiliation of external members and the location of the competition. After the reform, the distance is increased by approximately $80 \mathrm{~km}$ in associate professor competitions and by $65 \mathrm{~km}$ in full professor competitions. This confirms the intuition that when external selectors were elected there was a self-

\footnotetext{
${ }^{19} 9 \%$ of the competitions are excluded from the analysis because we could not recover their official final reports.

${ }^{20}$ An alternative reason for this increase is related to irregular time distribution of competitions over years, since only $6 \%$ of competitions took place in 2006, while no competition is observed in 2007 in our sample.

${ }^{21}$ The recruitment of full professors did not require any interview nor any teaching test if the applicant already held a position as associate professor.

${ }^{22}$ The increase in research quality of evaluators in competitions for associate professorship is partially a direct outcome of the reform, since it abolished the presence of two associate professors in the committee, leading to committees composed by full professors only. Also the increased variance has to be considered in this perspective.
} 
selection of near-by evaluators, who were more likely to be connected to the departments posting the vacancies.

Table 3 reports descriptive statistics for all applicants (columns 1 and 4), excluding candidates who eventually withdrew from the competition (columns 2 and 5) and for candidates who eventually qualified as professors (columns 3 and 6). Candidates applying in competitions for full (associate) professorships are on average 49 (43) year old and the share of female applicants is about $27 \%$ (37\%). These figures do not change restricting our attention on candidates who decided not to withdraw and on winners.

As regards the affiliation, before the reform, $23.9 \%$ of applicants for full professorships $(22.6 \%$ for associate positions) were insiders namely they were applying for vacancies posted by their departments of affiliation, while after the reform this proportion declined to $17.2 \%$ and $18.7 \%$, respectively. The percentage of insiders is slightly higher among those not withdrawing their application, in particular in competitions for associate professorship. Finally, the fraction of insiders is much higher as well as unaffected by the reform among the winners of competition. Note that a fraction of insiders close to $1 / 2$ among winners suggests that in general one insider was always selected among the two qualified (and she is also likely to having been hired by the department opening that vacancy). The average $\mathrm{H}$ index among all applicants before the reform is zero by construction (since standardisation is based on the pool of pre-reform applicants). It is slightly higher among qualified candidates and the applicants-winners differential is larger after the reform. While we cannot take this as a direct outcome of the reform, it is suggestive of an improvement as a result of randomly selecting the external selectors.

Table 3 about here

\section{Analysis}

To study the determinants of the probability of success among candidates - and the way it changed after the reform - we estimate a linear probability model with competition fixed effects. This way we control for unobservable systematic differences across disciplinary fields, locations and timing of the competitions. Thus, coefficients of the explanatory variables are identified exploiting their within competition variability, i.e. the differences between candidates taking part in the same competition.

We measure the effect of the applicant productivity (proxied by the standardized $\mathrm{H}$ index), age, gender and insider status, i.e. whether an applicant held a position at the department posting the vacancy ${ }^{23}$. To account for connections between candidates and selectors, we also include a dummy variable for candidates affiliated to the same university of an external selector.

Eventually, we add further interaction terms between the selectors' and the candidates' characteristics. We introduce a dummy taking value one when a female applicant is matched to a selecting committee composed only by men (DePaola and Scoppa 2015). We also include an interaction between the scientific productivity of the external selectors relative to the internal one and the scientific productivity of the candidate. It is a dummy variable equal to one when the external selectors are on average better than the internal one with respect to the $\mathrm{H}$ index multiplied by the $\mathrm{H}$ index of the candidate. This is to capture possible reversal in the bargaining power of external vs internal selectors driven by their scientific reputation.

As a robustness check we also re-estimate the equation replacing the $\mathrm{H}$-index by either the number of publications or the number of citations (also standardized by disciplinary fields in the same way as the H-index).

\footnotetext{
${ }^{23}$ By holding a position we mean that the applicant appears in the tenured faculty of the university opening the vacancy.
} 


\subsection{Competitions for associate professorship.}

Table 4 shows the estimates of the model for competitions for associate professorship. Results are presented separately for the pre- and post-reform periods and for bibliometric and non-bibliometric areas, respectively. We estimate our main regression on the entire pool of applicants - including those withdrawing from the competition - in order to measure an overall effect of the reform including the response both of applicants and of selection committees.

The most important individual characteristics for the probability of obtaining the qualification is by far a connection to the selectors. Before the reform being an insider increased the chances of success by 0.35 in bibliometric disciplines and by 0.40 in the non-bibliometric ones, while being an outsider with a selector from the same university increased the probability of success by 0.19 and 0.29 , respectively. ${ }^{24}$

After the reform the effect of being an insider is slightly smaller both in bibliometric and in nonbibliometric disciplines while the drop of the effect of having a selector from the same university is a bit larger, from 0.19 to 0.04 and from 0.29 to 0.19 , respectively. ${ }^{25}$ This is likely due to the random selection of external selectors which made less likely an ex-ante agreement among selectors. ${ }^{26}$

As for the role of the candidate scientific productivity, in line with expectations its effect is positive and statistically significant, but this effect is definitively small in magnitude, both before and after the reform. One standard deviation increase in the $\mathrm{H}$ index in bibliometric disciplines yields an effect as large as 0.05 and 0.04 before and after the reform, respectively. It is even smaller in non-bibliometric disciplines.

Adding the interaction between candidates and committee (regressions in even-numbered columns), does not yield any remarkable difference. Gender has no significant impact on the probability of success, also after controlling for the committee gender composition.

\section{Table 4 about here}

Table 5 presents the results for the decision of withdrawing the application. We are not surprised by the similarities of the results, since the estimates of table 4 are unconditional, and therefore incorporate the consequences of withdrawal. Here we find that the same factors affecting the likelihood of winning also affect the likelihood of withdrawing with a reversed sign. In particular, candidates who were outsider and/or did not have connections to the committee are more likely to withdraw. The reform seems to only alter the effect of being an outsider connected to a selector: this effect is negative and statistically significant both before and after the reform but much smaller after the reform, at least for bibliometric disciplines.

Consistently with the results from the regression for the probability of obtaining a qualification, the key result here is that the effect of being an insider is nearly unaffected by the reform. That is switching from elected to randomly chosen external selectors does not alter the overall advantage of being an insider (Table 4) nor the withdrawal decision (Table 5). After the reform age becomes relevant for the decision to withdraw both in bibliometric and in non-bibliometric disciplines, the probability of withdrawal decreasing with age up to 45 . Looking at the research productivity, we observe that better candidates have a lower probability to withdraw but the effect is statistically

\footnotetext{
${ }^{24}$ As shown in appendix A6, being an insider increases the probability to be qualified and hired by the university posting the vacancy, while being an outsider with a selector from the same university increases the probability of being qualified while being hired elsewhere.

${ }^{25}$ While we prefer splitting the sample in the two sub periods, which is equivalent to a fully interacted model. Following this strategy we can assess whether the changes in parameters are statistically significant or not. In such a case the drop in magnitude of the estimated coefficients for having a selector from the same university is statistically significant only for bibliometric fields.

${ }^{26}$ The negative effect of being an insider and of having a selector from the same university is statistically significant only in the bibliometric disciplines.
} 
significant only before the reform and in the bibliometric disciplines. There is no sign at all here of an effect of the reform on the role impact of the scientific record.

Table 5 about here

\subsection{Competitions for full professorship.}

In Table 6 we estimate the fixed effect linear probability model for the probability to qualify as a full professor. As in the case of competitions for associate professorship, connections to selectors play the most relevant role. Before the reform, local candidates had an advantage as large as 0.38 of being qualified in bibliometric research areas, while it was 0.52 in non-bibliometric ones. After the reform the advantage is slightly smaller in bibliometric disciplines while it declines to 0.32 , in nonbibliometric ones, the drop being statistically different from zero.

The role of connections to a selector from the same university changes in a similar way to the case of competitions for associate professorship, declining after the reform. It is interesting to note that before the reform the coefficients associated to scientific productivity had similar magnitudes in competitions for full and associate professorships, while after the reform only qualification to full professors in bibliometric sectors records an increase in magnitude: after the reform one standard deviation increase of the $\mathrm{H}$ index rises the likelihood of being qualified by 0.07 . However, as in the case of competitions for associate professorship this is definitely a minor effect (a one standard deviation increase amounts to 12 points in medicine or 5 points in mathematics).

Table 7 presents the results for the probability of withdrawal in full professorship competitions. The most relevant role is again played by the insider status, even if this effect is lower than in the case of associate professorship competitions. After the reform, this effect is approximately halved. All the other observable characteristics do not obtain a statistically significant estimate.

Table 6 about here

Table 7 about here

\subsection{Robustness checks}

The first robustness check we implemented is replacing the H-index as measure of scientific productivity in our models by either the number of publications or the number of citations. Results not reported here are entirely in line with those discussed above. We also re-estimated the models using a logistic regression instead of the linear probability model. Even in this case previous results are confirmed. ${ }^{27}$

Other possible sources of bias in our results have been considered. There might be measurement errors in the identification of candidates due to homonyms. However when excluding homonymous names we do not find significant differences in our results. Looking at Table A1 of Appendix and comparing it to columns 6 and 8 of table 4 , the statistical significance of the variables of interest does not change, although the magnitude of some coefficients varies.

\footnotetext{
${ }^{27}$ Tables for both cases are available from the authors on request.
} 
A further source of concern is the imperfect randomisation among the potential members of the committee, which were randomly drawn from an elected pool as large as three times the number of selectors to be appointed. Some research fields did not have at least 13 full professors (one to be appointed as internal member and 12 in the pool from which the Ministry could draw the final four), in which case no election took place, all professors were included in the pool and they were supplemented by professors belonging to related research fields in order to reach the required number of 12. We distinguish between the two cases - election+randomisation and pure randomisation - in tables A5 and A6 of Appendix. Estimates change a bit in the two cases with stronger effects of having connections in the subset of pure randomisation. Even if with lots of care due to the small sample size, this can be taken as an evidence of attenuation of these effects due to imperfect randomisation.

A final point regards the external validity of our results. In tables A7 and A8 we provide the distribution of the competitions by research area in our sample and in the entire Italian academia, finding that our sample over-represents the area of medical schools and underrepresents the schools of Economics and the schools of Law. Tables A9 and A10 display the time profile of the competitions and the (average) number of applicants: if we exclude some evidence of anticipation of competitions in 2004, we may conclude that our research strategy of selecting a subset of universities does not reduce the representativeness of our sample, reinforcing the external validity of our results.

\section{Summing up}

We have shown that changing the selection of recruiting committees partly affects some features of the behaviour of departments, selectors and candidates in four large Italian universities. In the prereform regime the recruiting committees were elected, the four external members belonged to geographically closer universities and had a lower scientific visibility, as measured by the standardised $\mathrm{H}$ index (also as a result of the presence of two associate professors among the four). The scientific standing of the internal member increased slightly after the reform and the random selection led to better qualified but more heterogeneous committees in competition for associate professorship. In addition, the fraction of competitions for full professorship with at least one woman in the committee rose to one half.

If the reform made it harder to preordain the outcome by affecting the composition of the selecting committee, the reaction of candidates internalised the increased uncertainty of the reformed competitions: the number of applicants doubled, while the fraction of withdrawals in competitions for associate professorships did not decline. The candidates then attracted were in large majority outsiders, less discouraged by being unknown to the department opening the vacancy: compared to being a full outsider and other things being equal, the random selection of committees increased the probability of being connected to one member for any candidate. Other observable characteristics of candidates (gender, age) did not seem affected by the reform, even if the differential in the scientific standing between those selected for qualification and pool of applicants is a bit higher after the reform.

Coming to the determinants of the probability of being qualified, Table 8 summarizes our main results drawing from tables 6 and 4 . The effect of being an insider on the probability of being selected just slightly decline for associates in bibliometric fields and full professors in non-bibliometric ones. As such, the reform was a complete failure, because it was unable to equalise the chance of being selected between insiders and outsiders. Nevertheless, in one respect the reform was effective, because it lowered the impact of being connected to a selector from a university other than the one opening the position: while before the reform it was large and statistically significant (possibly indicating the possibility of prearranged outcomes), it dropped in magnitude after the reform becoming statistically irrelevant in some of the specification we have considered.

Table 8 about here 
In a situation wherein the number of candidates is large and they are less likely to be known in advance to the committee, one would have expected an increase of the relevance of the (observable) scientific standing as a criterion for selection (the good view of connectedness as "information provider"). This is shown in figure 1, plotting the coefficients of table 8: there is a potential trade-off between the two dimensions, such that a decline in academic connections between candidates and selectors is accompanied by an increase in the impact of observable measures of scientific record. But the magnitude of the latter effect is small, as we have already noticed above.

This attenuated effect may be partly due to the institutional design, where each selecting committee was entitled to qualify up to two candidates per competition, watering the potential conflicts that arise whenever a committee has to designate a single winner. However, when we partition the qualified candidates according to their subsequent position (being hired by the department posting the vacancy or being hired elsewhere), we find that even in the latter case (which in principle could follow purely meritocratic criteria) the probability contribution of the observed track record remains small.

Figure 1 about here

\section{Concluding remarks}

Our results confirm that the reform intended to reduce cronyism and localism in the Italian universities has been only partially effective in raising the equality of opportunity for candidates who were not insiders. However this did not make selections more metric-based, since there is no clear evidence that the quality of selections improved. In addition, the reform came at some costs, which are not easy to evaluate. Randomisation makes the selection of bad selectors as equally likely as selecting good selectors. Before the reform a highly ranked department could have arranged a prestigious committee, which would have attracted good candidates and would have made credible any announcement that the best candidates would have been qualified. After the reform, such an announcement would have not considered as credible. In other words, randomisation implies levelling to the mean quality, which raises the bottom tail of the distribution but compresses the top one.

One could improve the quality of recruitment by introducing minimum requirements for being selected, as it has happened with the new national procedure for qualifications, where selectors and candidate are required to exhibit scientific productivity standards equivalent to the top half of the corresponding distribution (number of papers and number of citations). Participation requirements raise the issue of appropriate measurement of productivity: while in bibliometric research fields there is a widely accepted standard of using citations and impact factors as proxies for quality, in nonbibliometric areas such a consensus does not exist, and therefore it is rather arbitrary to define what a minimum threshold of productivity should be.

A clear limitation of our entire analysis is modelling selections as entirely based on scientific productivity. We all know that actual hiring takes into account other dimensions, like teaching, fundraising, agreeableness with colleagues and students, availability for administrative tasks. Unfortunately we do not have information on all these dimensions, which would make our exercise more evidence-based. In the future we hope to be able to enrich our dataset with information on the teaching loads performed by candidates, in order to consider alternative combinations of research and teaching as the driving forces for actual selections. 


\section{Appendix}

\section{A1. Homonimity:}

We exclude from the analysis candidates whose name is in common with at least another member of the Italian academia. We are not able to control for researchers outside universities, because we do not have information on researchers' names in other research institutions (like CNR) or health centres (like hospitals). However, comparing results in table A1, to results in table 4, columns 6 o 8, it turns out that at least that the pattern of statistical significance for the estimated coefficients does not vary even if in some instances the magnitude of the coefficients does not coincide.

Table A1 about here 


\section{A2. Timing of data collection of $\mathrm{H}$ index measures}

The analyses we present in this paper make use of an $\mathrm{H}$ index for candidates and for selectors collected in 2014. Clearly, this is not the $\mathrm{H}$ index obtainable for these individuals at the time when competitions took place. To investigate the potential bias arising from this approximation we have collected data on the $\mathrm{H}$ index at the time of the competition for a sub-sample of candidates in bibliometric research sectors ${ }^{28}$. This sub-sample is composed by two candidates in each macro research area and in each year of competitions. ${ }^{29}$

In particular, we consider two possible sources of bias. First, the bias resulting from replacing the true $\mathrm{H}$ index - i.e. the one at the time of the competition - with the $\mathrm{H}$ index measured in 2014 might depend on the age of the candidate. This would happen if the evolution over time of the $\mathrm{H}$ index depends on the age of the candidate, e.g. because the youngest candidates are more productive. To check this we split our sub-samples in two groups by age (above and below the median age in 2003). Then we plot the evolution over time from 2003 to 2014 of the average standardised $\mathrm{H}$ index separately for young and old candidates included in our sub-sample (see Figure A.1). There is a clear positive trend over time just slightly steeper for young candidates. Overall, this difference does not seem to introduce a relevant bias.

\section{Figure A1 about here}

The second possible bias refers to the different timing of competitions. Replacing the $\mathrm{H}$ index at the time of competition by the $\mathrm{H}$ index as of 2014 we introduce a measurement error that could be larger in older competitions. Let the measurement error be $\left(h_{i j t}-h_{i j t}^{*}\right)$ with $h_{i j t}^{*}$ being the $\mathrm{H}$ index at the time of competition for the $i$-th candidate in the $j$-th scientific field for a competition in year $t$ and $h_{i j t}$ the corresponding $\mathrm{H}$ index observed in 2014. The average measurement error in field $j$ for and year of competition $t$ is:

$$
\mu_{j t}=E\left[h_{i j t}-h_{i j t}^{*}\right]
$$

We then take the square of the deviation of the measurement error of the candidate $i$ in a competition of field $j$ in year $t$ from the average $\mu_{j t}$ :

$$
\left(h_{i j t}-h_{i j t}^{*}-\mu_{j t}\right)^{2}
$$

and regress it on a full set of dummy variables for the scientific fields and on three dummy for the time of competition (competitions in 2003-2004, in 2005-2006 and in 2008, respectively).

The reduction of the variance in the post-reform period (see Table A2) in principle might raise a concern since a smaller variance strictly speaking implies that the estimate of the coefficient on the $\mathrm{H}$ index is more biased toward zero in the pre-reform years. Otherwise stated, a reduction of the variance of the measurement error in the port-reform year implies that in Tables 4 and 6 we overstate the impact of the reform on the relevance of the $\mathrm{H}$ index. Since this variation is at best marginal - no variation in Table 4, small positive variation in Table 6 - we confidently conclude that the reform had a small - if any - effect on the relevance of the candidate $\mathrm{H}$ index for the outcome of the competition.

Table A2 here

\footnotetext{
${ }^{28}$ The $\mathrm{H}$ index is standardised using the field specific average and standard deviation of candidates included in the whole sample (see section 3).

${ }^{29}$ There are 14 macro areas of research (the so-called Area CUN), where all Italian academics are assigned to, depending on the research field they are pigeonholed when initially hired. The bibliometric sectors concern only 10 macro areas, which are observed over 5 years covered by our sample (from 2003 to 2006 and 2008): therefore we should have a theoretical sample of 100 candidates, both for full and associate professor competitions. However, we lose 4 candidates for full professorship because of the lack of competitions in one area for two years and we were forced to exclude another area (10 candidates) in competition for associate professorship due to too few candidates.
} 
A3. Standardizing the $H$ index of applicants and selectors.

Table A3 here

Table A4 here 
A4. Pure randomization vs election+ randomization. Does it make any difference?

Table A5 here

Table A6 here 
A5. Representativeness of our sample

Table A7 here

Table A8 here

Table A9 here

Table A10 here 


\section{A6. Effects on the probability to get the chair at the department opening the position and elsewhere.}

The competitions analysed in our sample awarded a maximum of two qualifications per competition, one very often assigned to an insider (who was then hired) and the other one assigned to other candidates. It is therefore possible that the effects of the reform manifested in the latter case, the former being the outcome of negotiations between internal and external selectors. We (arbitrarily) identify the former case whenever the qualified candidate is then hired by the department posting the vacancy, while the latter case applies otherwise. Tables 11 and 13 consider the probability of being qualified and hired by the department posting the vacancy, while tables 12 and 14 consider the probability of being qualified without being directly hired by the same department. Apart from the significance of the coefficient associated to being an insider, the relevant ones retain significance though magnitude changes across the assignment of the two qualifications. In particular, the coefficient associated to candidate scientific productivity and visibility (the $\mathrm{H}$ index) is slightly higher in the latter case than in the former.

Table A11 here

Table A12 here

Table A13 here

Table A14 here 


\section{References}

Allesina S. (2011) Measuring nepotism through shared last names: the case of Italian academia. PLoS one 6(8): e21160.

Bagues M., Sylos-Labini M., Zinovyeva N. (2015) Connections in Scientific Committees and Applicants' Self-Selection: Evidence from a Natural Randomized Experiment (No. 9594). Institute for the Study of Labor (IZA).

Bagues M., Sylos-Labini M., Zinovyeva N. (2017) Does the Gender Composition of Scientific Committees Matter?.American Economic Review 107(4): 1207-38

Checchi D., De Fraja G., Verzillo S. (2014) Publish or Perish? Incentives and Careers in Italian Academia (No. 10084). CEPR Discussion Papers.

De Paola M., Scoppa V. (2015) Gender discrimination and evaluators' gender: evidence from Italian academia. Economica 82(325): 162-188.

Durante R., Labartino G., Perotti R. (2011) Academic dynasties: decentralization and familism in the Italian academia (No. w17572). National Bureau of Economic Research.

Frey B., Steiner L. (2014) Random selection in politics, science and society: applications and institutional embeddedness. CREMA wp. 2014-09

Goodal A., Osterloh M. (2015) Women Have to Enter the Leadership Race to Win: Using Random Selection to Increase the Supply of Women into Senior Positions. IZA wp.9931

Godechot O. (2016) The chance of influence: A natural experiment on the role of social capital in faculty recruitment. Social Networks 46: 60-75.

Moss D. (2012) When Patronage Meets Meritocracy: Or, The Italian Academic Concorso As Cockfight. European Journal of Sociology 53(02): 205-231.

Perotti, R. (2008). L'università truccata. Torino, Einaudi.

Zinovyeva N., Bagues M. (2015) The role of connections in academic promotions. American Economic Journal: Applied Economics 7(2): 264-292. 
Figure 1 - Potential trade-off between connectedness and scientific record

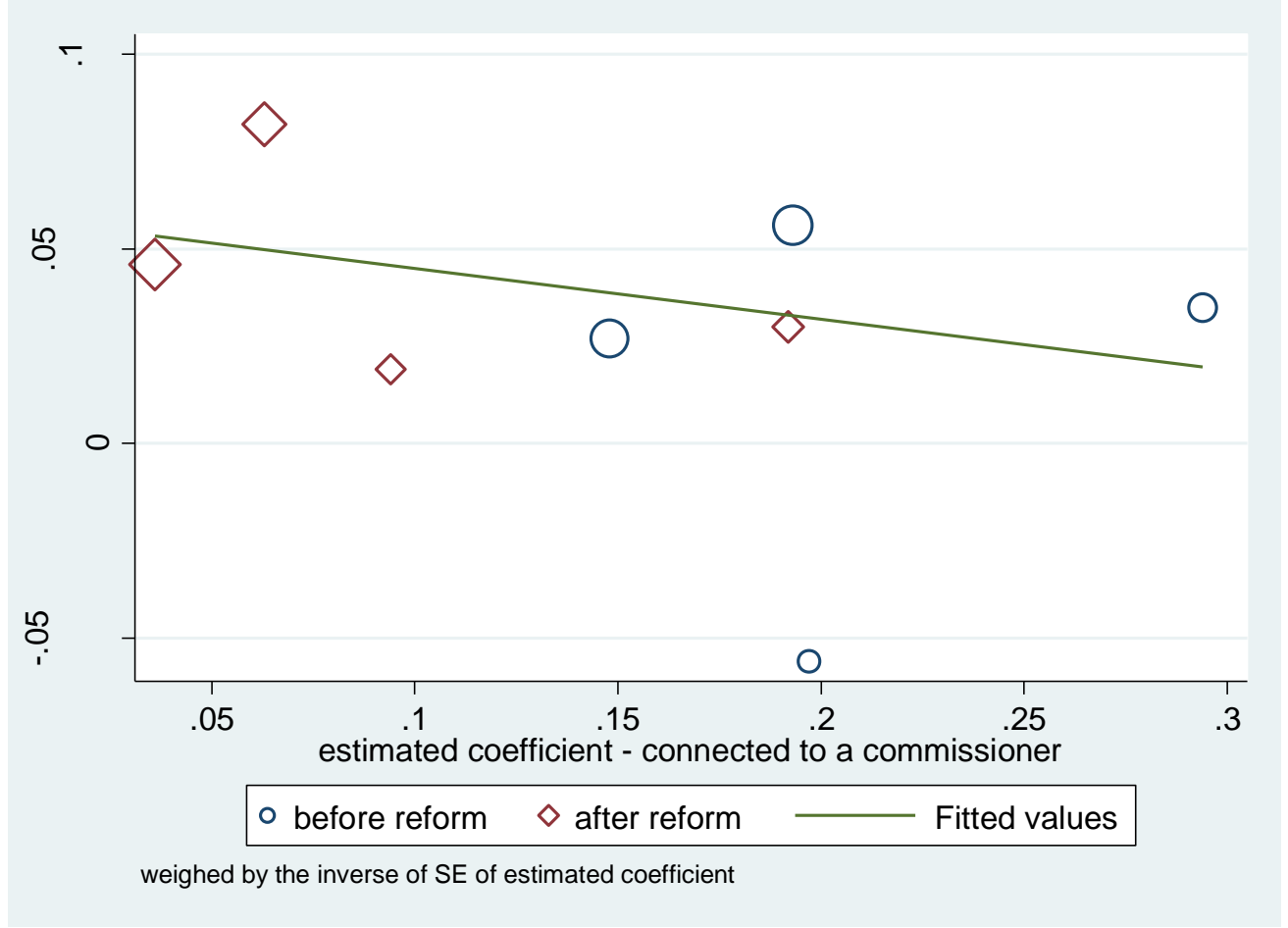

Figure A.1 - Trend of the standardised H index between 2003 and 2014 of 96 candidates for full professorship and 90 for associate professorship.
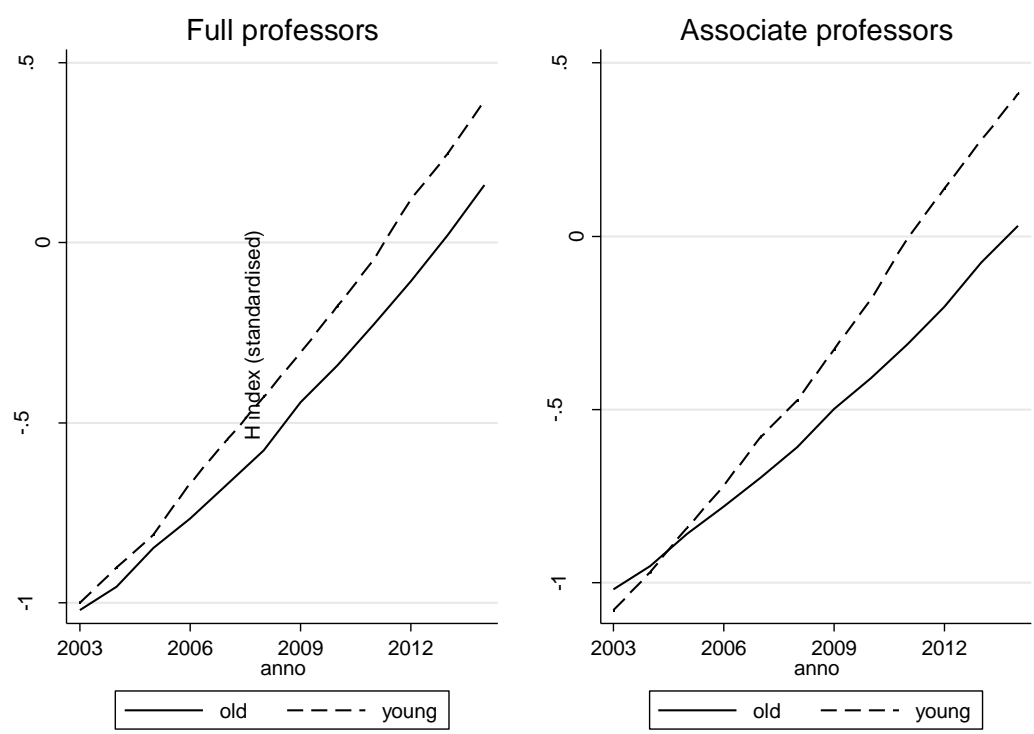
Tables

Table 1 - Descriptive statistics of competitions for professorship, years 2003 to 2008, University of Padua, Milan - Statale, Rome - La Sapienza, Naples - Federico II.

\begin{tabular}{|c|c|c|c|c|c|c|}
\hline & \multicolumn{3}{|c|}{ Before the reform (2003-2007) } & \multicolumn{3}{|c|}{ After the reform (2008) } \\
\hline & All & $\begin{array}{c}\text { Non } \\
\text { bibliometric }\end{array}$ & $\begin{array}{l}\text { Biblio- } \\
\text { metric }\end{array}$ & All & $\begin{array}{c}\text { Non } \\
\text { bibliometric }\end{array}$ & $\begin{array}{l}\text { Biblio- } \\
\text { metric }\end{array}$ \\
\hline & \multicolumn{6}{|c|}{ Full professors } \\
\hline $\begin{array}{l}\text { Average number of } \\
\text { candidates }\end{array}$ & 8.8 & 5.8 & 10.0 & 16.1 & 13.6 & 16.9 \\
\hline$\%$ of withdrawals & 20.1 & 17.2 & 21.2 & 11.3 & 12.2 & 11.0 \\
\hline \multirow{2}{*}{ Number of competitions } & 138 & 38 & 100 & 92 & 22 & 70 \\
\hline & \multicolumn{6}{|c|}{ Associate professors } \\
\hline $\begin{array}{l}\text { Average number of } \\
\text { candidates }\end{array}$ & 9.6 & 7.7 & 10.3 & 18.7 & 14.8 & 20.1 \\
\hline$\%$ of withdrawals & 50.0 & 40.8 & 53.3 & 47.4 & 39.3 & 50.4 \\
\hline Number of competitions & 273 & 72 & 201 & 161 & 43 & 118 \\
\hline
\end{tabular}

Table 2 - Descriptive statistics of selecting committees, years 2003 to 2008, University of Padua, Milan Statale, Rome - La Sapienza, Naples - Federico II* .

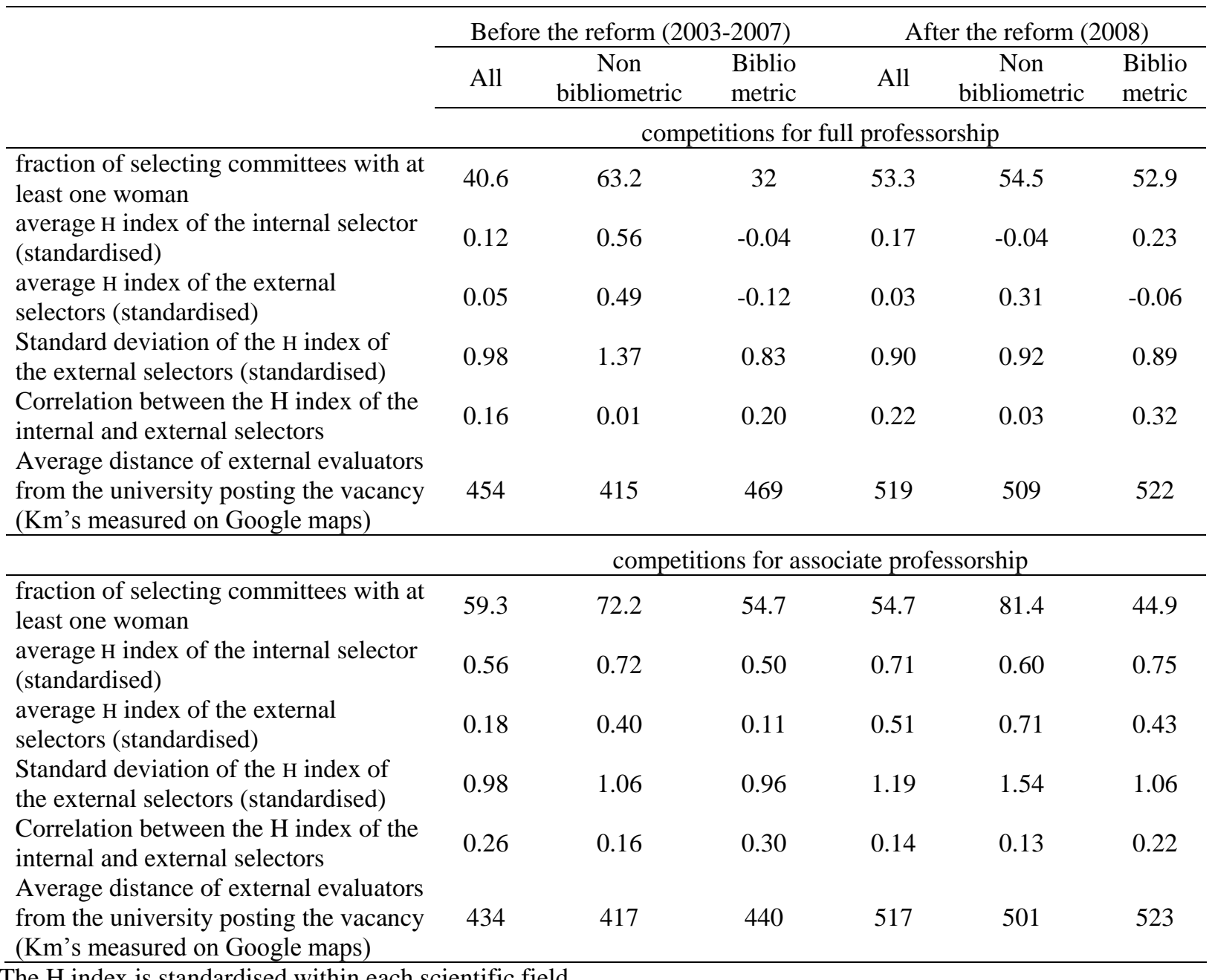

* The H index is standardised within each scientific field. 
Table 3 - Descriptive statistics of candidates, years 2003 to 2008, University of Padua, Milan - Statale, Rome - La Sapienza, Naples - Federico II.

\begin{tabular}{|c|c|c|c|c|c|c|}
\hline & \multicolumn{3}{|c|}{ Before the reform (2003-2007) } & \multicolumn{3}{|c|}{ After the reform (2008) } \\
\hline & All & $\begin{array}{c}\text { Net of } \\
\text { withdrawals }\end{array}$ & Qualified & All & $\begin{array}{c}\text { Net of } \\
\text { withdrawals }\end{array}$ & Qualified \\
\hline & \multicolumn{6}{|c|}{ Full professors } \\
\hline Share of female & 27.4 & 27.5 & 27.2 & 26.8 & 27.2 & 28.1 \\
\hline Age & 48.3 & 48.7 & 48.8 & 50.0 & 50.0 & 49.5 \\
\hline $\begin{array}{l}\text { Share of insiders } \\
\mathrm{H} \text { index }\end{array}$ & 23.9 & 26.7 & 54.1 & 17.2 & 18.2 & 53.4 \\
\hline (standardised) & 0.00 & -0.05 & 0.12 & 0.05 & 0.04 & 0.30 \\
\hline \multirow[t]{2}{*}{ Total } & 1217 & 975 & 246 & 1480 & 1325 & 178 \\
\hline & \multicolumn{6}{|c|}{ Associate professors } \\
\hline Share of female & 37.2 & 36.8 & 36.0 & 38.1 & 35.2 & 37.3 \\
\hline Age & 42.5 & 43.1 & 43.6 & 43.0 & 43.1 & 43.8 \\
\hline $\begin{array}{l}\text { Share of insiders } \\
\mathrm{H} \text { index }\end{array}$ & 22.6 & 34.4 & 50.2 & 18.7 & 27.1 & 49.4 \\
\hline (standardised) & 0.00 & 0.01 & 0.11 & -0.01 & 0.03 & 0.23 \\
\hline Total & 2619 & 1152 & 506 & 3010 & 1541 & 308 \\
\hline
\end{tabular}


Table 4 - Fixed effect linear probability model for the probability of winning a competition for associate professorship, years 2003 to 2008 , University of Padua, Milan - Statale, Rome - La Sapienza, Naples - Federico II.

\begin{tabular}{|c|c|c|c|c|c|c|c|c|}
\hline & \multicolumn{4}{|c|}{ Bibliometric } & \multicolumn{4}{|c|}{ Non Bibliometric } \\
\hline & $\begin{array}{c}(1) \\
\text { Before }\end{array}$ & $\begin{array}{c}(2) \\
\text { Before }\end{array}$ & $\begin{array}{c}\text { (3) } \\
\text { After }\end{array}$ & $\begin{array}{c}(4) \\
\text { After }\end{array}$ & $\begin{array}{c}(5) \\
\text { Before }\end{array}$ & $\begin{array}{c}(6) \\
\text { Before }\end{array}$ & $\begin{array}{c}(7) \\
\text { After }\end{array}$ & $\begin{array}{c}(8) \\
\text { After }\end{array}$ \\
\hline $\mathrm{H}$ index & $\begin{array}{c}0.047 * * * \\
(0.010)\end{array}$ & $\begin{array}{c}0.056 * * * \\
(0.013)\end{array}$ & $\begin{array}{c}0.042 * * * \\
(0.009)\end{array}$ & $\begin{array}{c}0.046^{* * * *} \\
(0.012)\end{array}$ & $\begin{array}{c}0.040 * * \\
(0.017)\end{array}$ & $\begin{array}{c}0.035 \\
(0.035)\end{array}$ & $\begin{array}{c}0.014 \\
(0.013)\end{array}$ & $\begin{array}{c}0.030 \\
(0.023)\end{array}$ \\
\hline Age & $\begin{array}{l}-0.021 \\
(0.016)\end{array}$ & $\begin{array}{l}-0.021 \\
(0.016)\end{array}$ & $\begin{array}{c}0.009 \\
(0.009)\end{array}$ & $\begin{array}{c}0.009 \\
(0.009)\end{array}$ & $\begin{array}{l}-0.012 \\
(0.024)\end{array}$ & $\begin{array}{l}-0.014 \\
(0.024)\end{array}$ & $\begin{array}{c}0.008 \\
(0.017)\end{array}$ & $\begin{array}{c}0.009 \\
(0.018)\end{array}$ \\
\hline $\mathrm{Age}^{2} / 1000$ & $\begin{array}{c}0.269 \\
(0.178)\end{array}$ & $\begin{array}{c}0.276 \\
(0.178)\end{array}$ & $\begin{array}{l}-0.095 \\
(0.100)\end{array}$ & $\begin{array}{l}-0.094 \\
(0.101)\end{array}$ & $\begin{array}{c}0.125 \\
(0.264)\end{array}$ & $\begin{array}{c}0.149 \\
(0.265)\end{array}$ & $\begin{array}{l}-0.097 \\
(0.201)\end{array}$ & $\begin{array}{c}-0.102 \\
(0.203)\end{array}$ \\
\hline Female & $\begin{array}{c}0.002 \\
(0.020)\end{array}$ & $\begin{array}{l}-0.000 \\
(0.023)\end{array}$ & $\begin{array}{l}-0.009 \\
(0.012)\end{array}$ & $\begin{array}{l}-0.016 \\
(0.015)\end{array}$ & $\begin{array}{l}-0.054 \\
(0.036)\end{array}$ & $\begin{array}{l}-0.073 \\
(0.047)\end{array}$ & $\begin{array}{l}-0.026 \\
(0.030)\end{array}$ & $\begin{array}{c}-0.020 \\
(0.034)\end{array}$ \\
\hline Female $\times$ No female evaluators & & $\begin{array}{c}0.006 \\
(0.042)\end{array}$ & & $\begin{array}{c}0.015 \\
(0.026)\end{array}$ & & $\begin{array}{c}0.060 \\
(0.074)\end{array}$ & & $\begin{array}{c}-0.025 \\
(0.069)\end{array}$ \\
\hline $\begin{array}{l}\text { External above internal } \times \mathrm{H} \text { index } \\
\text { candidate }\end{array}$ & & $\begin{array}{l}-0.025 \\
(0.020)\end{array}$ & & $\begin{array}{l}-0.008 \\
(0.018)\end{array}$ & & $\begin{array}{c}0.007 \\
(0.039)\end{array}$ & & $\begin{array}{l}-0.023 \\
(0.027)\end{array}$ \\
\hline Insider & $\begin{array}{c}0.346 * * * \\
(0.026)\end{array}$ & $\begin{array}{c}0.345^{* * * *} \\
(0.026)\end{array}$ & $\begin{array}{c}0.220 * * * \\
(0.023)\end{array}$ & $\begin{array}{c}0.219 * * * \\
(0.023)\end{array}$ & $\begin{array}{c}0.395 * * * \\
(0.059)\end{array}$ & $\begin{array}{c}0.394 * * * \\
(0.059)\end{array}$ & $\begin{array}{c}0.330 * * * \\
(0.057)\end{array}$ & $\begin{array}{c}0.329 * * * \\
(0.057)\end{array}$ \\
\hline Selector of the same university & $\begin{array}{c}0.192 * * * \\
(0.030)\end{array}$ & $\begin{array}{c}0.193 * * * \\
(0.030)\end{array}$ & $\begin{array}{l}0.036^{*} \\
(0.022)\end{array}$ & $\begin{array}{l}0.036^{*} \\
(0.022)\end{array}$ & $\begin{array}{c}0.292 * * * \\
(0.055)\end{array}$ & $\begin{array}{c}0.294 * * * \\
(0.054)\end{array}$ & $\begin{array}{c}0.191 * * * \\
(0.059)\end{array}$ & $\begin{array}{c}0.192 * * * \\
(0.060)\end{array}$ \\
\hline Constant & $\begin{array}{c}0.461 \\
(0.337)\end{array}$ & $\begin{array}{c}0.472 \\
(0.337)\end{array}$ & $\begin{array}{c}-0.148 \\
(0.201)\end{array}$ & $\begin{array}{c}-0.147 \\
(0.202)\end{array}$ & $\begin{array}{c}0.414 \\
(0.515)\end{array}$ & $\begin{array}{c}0.460 \\
(0.516)\end{array}$ & $\begin{array}{c}-0.098 \\
(0.376)\end{array}$ & $\begin{array}{c}-0.104 \\
(0.379)\end{array}$ \\
\hline Observations & 2,062 & 2,062 & 2,374 & 2,374 & 557 & 557 & 636 & 636 \\
\hline $\mathrm{R}^{2}$ & 0.144 & 0.144 & 0.093 & 0.094 & 0.174 & 0.175 & 0.130 & 0.132 \\
\hline Number of competitions & 201 & 201 & 118 & 118 & 72 & 72 & 43 & 43 \\
\hline
\end{tabular}

Heteroscedasticity robust standard errors in parentheses, clustered at competition level - competition fixed effects included statistical significance $* * * \mathrm{p}<0.01, * * \mathrm{p}<0.05, * \mathrm{p}<0.1$ 
Table 5 - Fixed effect linear probability model for the probability of withdrawing from a competition for associate professorship, years 2003 to 2008, University of Padua, Milan - Statale, Rome - La Sapienza, Naples - Federico II.

\begin{tabular}{|c|c|c|c|c|}
\hline & \multicolumn{2}{|c|}{ Bibliometric } & \multicolumn{2}{|c|}{ Non Bibliometric } \\
\hline & Before & After & Before & After \\
\hline \multirow[t]{2}{*}{ H index } & $-0.048 * * *$ & -0.018 & -0.012 & 0.029 \\
\hline & $(0.017)$ & $(0.019)$ & $(0.040)$ & $(0.035)$ \\
\hline \multirow[t]{2}{*}{ Age } & 0.004 & $-0.064 * * *$ & -0.013 & $-0.066 * * *$ \\
\hline & $(0.018)$ & $(0.017)$ & $(0.026)$ & $(0.023)$ \\
\hline \multirow[t]{2}{*}{$\mathrm{Age}^{2} / 1000$} & -0.094 & $0.701 * * *$ & 0.130 & $0.744 * * *$ \\
\hline & $(0.203)$ & $(0.186)$ & $(0.284)$ & $(0.262)$ \\
\hline \multirow[t]{2}{*}{ Female } & -0.003 & $0.075 * * *$ & 0.044 & 0.059 \\
\hline & $(0.032)$ & $(0.027)$ & $(0.053)$ & $(0.053)$ \\
\hline \multirow[t]{2}{*}{ Female $\times$ No female evaluators } & -0.026 & -0.000 & -0.045 & -0.064 \\
\hline & $(0.054)$ & $(0.043)$ & $(0.102)$ & $(0.105)$ \\
\hline \multirow{2}{*}{$\begin{array}{l}\text { External above internal } \times \mathrm{H} \text { index } \\
\text { candidate }\end{array}$} & 0.012 & $-0.044 *$ & 0.002 & -0.038 \\
\hline & $(0.025)$ & $(0.026)$ & $(0.051)$ & $(0.041)$ \\
\hline \multirow[t]{2}{*}{ Insider } & $-0.333 * * *$ & $-0.326 * * *$ & $-0.300 * * *$ & $-0.284 * * *$ \\
\hline & $(0.026)$ & $(0.025)$ & $(0.055)$ & $(0.046)$ \\
\hline \multirow[t]{2}{*}{ Selector from the same university } & $-0.189 * * *$ & $-0.066^{*}$ & $-0.177 * *$ & $-0.166 * *$ \\
\hline & $(0.036)$ & $(0.034)$ & $(0.068)$ & $(0.068)$ \\
\hline \multirow[t]{2}{*}{ Constant } & $0.704^{*}$ & $1.959 * * *$ & 0.862 & $1.910 * * *$ \\
\hline & $(0.399)$ & $(0.382)$ & $(0.581)$ & $(0.520)$ \\
\hline Observations & 2,026 & 2,374 & 557 & 636 \\
\hline $\mathrm{R}^{2}$ & 0.092 & 0.080 & 0.069 & 0.063 \\
\hline Number of competitions & 198 & 118 & 72 & 43 \\
\hline
\end{tabular}

Heteroscedasticity robust standard errors in parentheses, clustered at competition level - competition fixed effects included - statistical significance $* * * \mathrm{p}<0.01, * * \mathrm{p}<0.05, * \mathrm{p}<0.1$ - Note: three competitions were excluded because the final report was incomplete and we could not observe the name of candidates who withdrew. 
Table 6 - Fixed effect linear probability model for the probability of winning a competition for full professorship, years 2003 to 2008 , University of Padua, Milan - Statale, Rome - La Sapienza, Naples - Federico II.

\begin{tabular}{|c|c|c|c|c|c|c|c|c|}
\hline & \multicolumn{4}{|c|}{ Bibliometric } & \multicolumn{4}{|c|}{ Non Bibliometric } \\
\hline & $(1)$ & (2) & (3) & $(4)$ & $(5)$ & (6) & (7) & $(8)$ \\
\hline & Before & Before & After & After & Before & Before & After & After \\
\hline \multirow[t]{2}{*}{$\mathrm{H}$ index } & $0.033 * *$ & 0.027 & $0.073 * * *$ & $0.082 * * *$ & 0.024 & $-0.056^{*}$ & -0.006 & 0.019 \\
\hline & $(0.016)$ & $(0.023)$ & $(0.012)$ & $(0.016)$ & $(0.031)$ & $(0.031)$ & $(0.012)$ & $(0.025)$ \\
\hline \multirow[t]{2}{*}{ Age } & 0.008 & 0.008 & 0.012 & 0.012 & -0.070 & -0.069 & $0.062 *$ & $0.063 *$ \\
\hline & $(0.016)$ & $(0.016)$ & $(0.013)$ & $(0.013)$ & $(0.055)$ & $(0.054)$ & $(0.032)$ & $(0.032)$ \\
\hline \multirow[t]{2}{*}{$\mathrm{Age}^{2} / 1000$} & -0.089 & -0.094 & -0.132 & -0.132 & 0.641 & 0.626 & $-0.651 * *$ & $-0.664 * *$ \\
\hline & $(0.167)$ & $(0.169)$ & $(0.124)$ & $(0.123)$ & $(0.542)$ & $(0.529)$ & $(0.292)$ & $(0.287)$ \\
\hline \multirow[t]{2}{*}{ Female } & -0.019 & -0.064 & 0.008 & 0.010 & -0.014 & 0.006 & -0.027 & 0.000 \\
\hline & $(0.026)$ & $(0.044)$ & $(0.024)$ & $(0.032)$ & $(0.072)$ & $(0.071)$ & $(0.045)$ & $(0.053)$ \\
\hline \multirow[t]{2}{*}{ Female $\times$ No female evaluators } & & 0.066 & & -0.002 & & 0.008 & & -0.085 \\
\hline & & $(0.055)$ & & $(0.047)$ & & $(0.157)$ & & $(0.083)$ \\
\hline \multirow{2}{*}{$\begin{array}{l}\text { External above internal } \times \mathrm{H} \text { index } \\
\text { candidate }\end{array}$} & & 0.011 & & -0.018 & & $0.156 * * *$ & & -0.036 \\
\hline & & $(0.031)$ & & $(0.023)$ & & $(0.049)$ & & $(0.031)$ \\
\hline \multirow[t]{2}{*}{ Insider } & $0.383 * * *$ & $0.383 * * *$ & $0.339 * * *$ & $0.339 * * *$ & $0.520 * * *$ & $0.522 * * *$ & $0.324 * * *$ & $0.331 * * *$ \\
\hline & $(0.037)$ & $(0.037)$ & $(0.036)$ & $(0.036)$ & $(0.076)$ & $(0.078)$ & $(0.048)$ & $(0.049)$ \\
\hline \multirow[t]{2}{*}{ Selector from the same university } & $0.147 * * *$ & $0.148 * * *$ & $0.062 * *$ & $0.063 * *$ & $0.189 *$ & $0.197 * *$ & 0.085 & 0.094 \\
\hline & $(0.031)$ & $(0.031)$ & $(0.031)$ & $(0.031)$ & $(0.103)$ & $(0.096)$ & $(0.065)$ & $(0.065)$ \\
\hline \multirow[t]{2}{*}{ Constant } & -0.095 & -0.110 & -0.228 & -0.228 & 2.006 & 1.990 & -1.330 & -1.347 \\
\hline & $(0.391)$ & $(0.395)$ & $(0.337)$ & $(0.333)$ & $(1.381)$ & $(1.346)$ & $(0.877)$ & $(0.868)$ \\
\hline Observations & 995 & 995 & 1,180 & 1,180 & 222 & 222 & 300 & 300 \\
\hline $\mathrm{R}^{2}$ & 0.164 & 0.165 & 0.182 & 0.183 & 0.236 & 0.265 & 0.133 & 0.139 \\
\hline Number of competitions & 100 & 100 & 70 & 70 & 38 & 38 & 22 & 22 \\
\hline
\end{tabular}

Heteroscedasticity robust standard errors in parentheses, clustered at competition level - competition fixed effects included - statistical significance $* * * p<0.01, * * p<0.05, *$ $\mathrm{p}<0.1$ 
Table 7 - Fixed effect linear probability model for the probability of withdrawing from a competition for full professorship, years 2003 to 2008, University of Padua, Milan - Statale, Rome - La Sapienza, Naples Federico II.

\begin{tabular}{|c|c|c|c|c|}
\hline & \multicolumn{2}{|c|}{ Bibliometric } & \multicolumn{2}{|c|}{ Non Bibliometric } \\
\hline & Before & After & Before & After \\
\hline \multirow[t]{2}{*}{ H index } & 0.015 & 0.021 & $0.095^{*}$ & 0.002 \\
\hline & $(0.020)$ & $(0.015)$ & $(0.047)$ & $(0.019)$ \\
\hline \multirow[t]{2}{*}{ Age } & $-0.046^{*}$ & 0.004 & 0.034 & $-0.068 *$ \\
\hline & $(0.025)$ & $(0.015)$ & $(0.042)$ & $(0.036)$ \\
\hline \multirow[t]{2}{*}{$\mathrm{Age}^{2} / 1000$} & 0.366 & -0.043 & -0.358 & $0.629 *$ \\
\hline & $(0.261)$ & $(0.142)$ & $(0.405)$ & $(0.336)$ \\
\hline \multirow[t]{2}{*}{ Female } & 0.015 & -0.020 & -0.008 & -0.015 \\
\hline & $(0.054)$ & $(0.031)$ & $(0.048)$ & $(0.040)$ \\
\hline \multirow[t]{2}{*}{ Female $\times$ No female evaluators } & -0.020 & 0.015 & 0.079 & 0.001 \\
\hline & $(0.065)$ & $(0.045)$ & $(0.116)$ & $(0.077)$ \\
\hline \multirow{2}{*}{ External above internal $\times \mathrm{H}$ index candidate } & -0.012 & 0.025 & -0.089 & -0.016 \\
\hline & $(0.027)$ & $(0.021)$ & $(0.061)$ & $(0.022)$ \\
\hline \multirow[t]{2}{*}{ Insider } & $-0.103 * * *$ & $-0.047 * *$ & $-0.178 * * *$ & $-0.072 *$ \\
\hline & $(0.031)$ & $(0.022)$ & $(0.045)$ & $(0.040)$ \\
\hline \multirow[t]{2}{*}{ Selector from the same university } & $-0.067 *$ & 0.016 & -0.052 & 0.039 \\
\hline & $(0.036)$ & $(0.037)$ & $(0.060)$ & $(0.053)$ \\
\hline \multirow[t]{2}{*}{ Constant } & $1.603 * * *$ & -0.001 & -0.556 & $1.947 * *$ \\
\hline & $(0.590)$ & $(0.392)$ & $(1.058)$ & $(0.936)$ \\
\hline Observations & 995 & 1,180 & 222 & 300 \\
\hline $\mathrm{R}^{2}$ & 0.059 & 0.013 & 0.097 & 0.030 \\
\hline Number of competitions & 100 & 70 & 38 & 22 \\
\hline
\end{tabular}

Heteroscedasticity robust standard errors in parentheses, clustered at competition level, competition fixed effect statistical significance $* * * \mathrm{p}<0.01, * * \mathrm{p}<0.05, * \mathrm{p}<0.1$

Table 8 - Summary of results

\begin{tabular}{|c|c|c|c|c|c|c|c|c|}
\hline & \multicolumn{4}{|c|}{ Bibliometric } & \multicolumn{4}{|c|}{ Non bibliometric } \\
\hline & \multicolumn{2}{|c|}{ Associate } & \multicolumn{2}{|c|}{ Full } & \multicolumn{2}{|c|}{ Associate } & \multicolumn{2}{|c|}{ Full } \\
\hline & before & After & before & after & before & After & before & after \\
\hline \multirow[t]{2}{*}{ H index } & $0.056 * * *$ & $0.046^{* * *} *$ & 0.027 & $0.082 * * *$ & 0.035 & 0.030 & $-0.056^{*}$ & 0.019 \\
\hline & $(0.013)$ & $(0.012)$ & $(0.023)$ & $(0.016)$ & $(0.035)$ & $(0.023)$ & $(0.031)$ & $(0.025)$ \\
\hline \multirow[t]{2}{*}{ Insider } & $0.345 * * *$ & $0.219 * * *$ & $0.383 * * *$ & $0.339 * * *$ & $0.394 * * *$ & $0.329 * * *$ & $0.522 * * *$ & $0.331 * * *$ \\
\hline & $(0.026)$ & $(0.023)$ & $(0.037)$ & $(0.036)$ & $(0.059)$ & $(0.057)$ & $(0.078)$ & $(0.049)$ \\
\hline Selector from & $0.193 * * *$ & $0.036^{*}$ & $0.148 * * *$ & $0.063 * *$ & $0.294 * * *$ & $0.192 * * *$ & $0.197 * *$ & 0.094 \\
\hline same university & $(0.030)$ & $(0.022)$ & $(0.031)$ & $(0.031)$ & $(0.054)$ & $(0.060)$ & $(0.096)$ & $(0.065)$ \\
\hline
\end{tabular}

\section{Appendix}


Table A15 - The effect of individual characteristics on candidates' success excluding candidates with at least one homonymous scholar in the Italian academia. Competition for associate professorship.

\begin{tabular}{lcc}
\hline & \multicolumn{2}{c}{ Non bibliometric } \\
& Before & After \\
\hline \multirow{2}{*}{ H index } & $0.031^{*}$ & 0.015 \\
Age & $(0.017)$ & $(0.011)$ \\
& -0.016 & 0.009 \\
Age $2 / 1000$ & $(0.023)$ & $(0.018)$ \\
& 0.156 & -0.100 \\
Female & $(0.263)$ & $(0.200)$ \\
& $-0.084 *$ & -0.021 \\
Female $\times$ No female evaluators & $(0.046)$ & $(0.035)$ \\
& 0.062 & -0.018 \\
Insider & $(0.072)$ & $(0.067)$ \\
Selector from the same university & $0.404^{* * *}$ & $0.348^{* * *}$ \\
& $(0.062)$ & $(0.061)$ \\
Constant & $0.294^{* * *}$ & $0.207 * * *$ \\
& $(0.059)$ & $(0.061)$ \\
Observations & 0.501 & -0.110 \\
$\mathrm{R}^{2}$ & $(0.504)$ & $(0.380)$ \\
Number of competitions & & \\
\hline
\end{tabular}

Heteroscedasticity robust standard errors in parentheses, clustered at competition level, including competition fixed effects - statistical significance $* * * \mathrm{p}<0.01, * * \mathrm{p}<0.05, * \mathrm{p}<0.1$ 
Table A16 - OLS model of the variability of the measurement error of $\mathrm{H}$ index. Candidates to associate and full professorship.

\begin{tabular}{lcc}
\hline & Associate & Full \\
\hline \multirow{2}{*}{ Years: 2005-2006 } & -0.159 & -0.154 \\
& $(0.138)$ & $(0.177)$ \\
Year: 2008 & $-0.485^{* * *}$ & -0.235 \\
& $(0.169)$ & $(0.213)$ \\
Research areas (areaCUN) & & \\
ac2 & -0.034 & 0.168 \\
& $(0.262)$ & $(0.395)$ \\
ac3 & -0.057 & -0.0257 \\
& $(0.262)$ & $(0.338)$ \\
ac4 & 0.184 & -0.103 \\
& $(0.262)$ & $(0.338)$ \\
ac5 & -0.127 & -0.284 \\
& $(0.262)$ & $(0.338)$ \\
ac6 & 0.060 & -0.258 \\
& $(0.262)$ & $(0.338)$ \\
ac7 & 0.251 & $0.777 * *$ \\
& $(0.262)$ & $(0.338)$ \\
ac9 & $0.808^{* * *}$ & 0.104 \\
& $(0.262)$ & $(0.338)$ \\
ac11 & 0.040 & -0.099 \\
& $(0.262)$ & $(0.338)$ \\
ac8 & & 0.059 \\
& & $(0.338)$ \\
Intercept & $0.419 * *$ & 0.411 \\
& $(0.200)$ & $(0.258)$ \\
Observations & & \\
R-squared & 90 & 96 \\
andard errors in parentheses - statistical significance *** p<0.01, & $* * 150.05, * \mathrm{p}<0.1$ \\
& & \\
& 0.253 & \\
& &
\end{tabular}


Table A17 - Mean and standard deviation of the $\mathrm{H}$ index by research area - candidates to associate professorships - years 2003-2005 (before the reform).

\begin{tabular}{cclccc}
\hline bibliometric & $\begin{array}{c}\text { research } \\
\text { area } \\
\text { areaCUN) }\end{array}$ & \multicolumn{1}{c}{ research area } & $\begin{array}{c}\text { MEAN H } \\
\text { index }\end{array}$ & $\begin{array}{c}\text { st.dev. H } \\
\text { index }\end{array}$ & N obs \\
\hline 1 & 1 & Mathematics and informatics & 8.2 & 6.5 & 239 \\
1 & 2 & Physics & 19.6 & 12.1 & 159 \\
1 & 3 & Chemistry & 19.5 & 8.2 & 156 \\
1 & 4 & Earth sciences & 10.4 & 6.2 & 112 \\
1 & 5 & Biology & 18.4 & 9.3 & 254 \\
1 & 6 & Medicine & 9.4 & 10.9 & 763 \\
1 & 7 & Agricultural and veterinary sciences & 6.5 & 204 \\
1 & 8 & Civil engineering & 8.3 & 4.3 & 16 \\
1 & 9 & Industrial and information engineering & 9.7 & 5.8 & 118 \\
& & Antiquities, philology, literary studies, art & & & \\
0 & 10 & history & 2.6 & 2.3 & 77 \\
1 & 11 & Psychology & 7.1 & 7.5 & 41 \\
0 & 12 & Law studies & 9.1 & 7.6 & 100 \\
0 & 13 & Economics and statistics & 7.7 & 6.0 & 96 \\
0 & 14 & Political and social sciences & 3.7 & 6.1 & 84 \\
0 & 8 & Architecture & 6.3 & 124 \\
0 & 11 & History, philosophy, pedagogy & 6.0 & 5.5 & 76 \\
\hline
\end{tabular}

Table A18 - Mean and standard deviation of the $\mathrm{H}$ index by research area - candidates to full professorships - years 2003-2005 (before the reform).

\begin{tabular}{cclccc}
\hline bibliometric & $\begin{array}{c}\text { research } \\
\text { area } \\
\text { areaCUN) }\end{array}$ & \multicolumn{1}{c}{ research area } & $\begin{array}{c}\text { MEAN H } \\
\text { index }\end{array}$ & $\begin{array}{c}\text { st.dev. H } \\
\text { index }\end{array}$ & N obs \\
\hline 1 & 1 & Mathematics and informatics & 9.0 & 5.0 & 129 \\
1 & 2 & Physics & 23.8 & 15.3 & 61 \\
1 & 3 & Chemistry & 20.0 & 9.8 & 111 \\
1 & 4 & Earth sciences & 12.8 & 8.5 & 32 \\
1 & 5 & Biology & 18.3 & 10.4 & 155 \\
1 & 6 & Medicine & 8.8 & 12.4 & 313 \\
1 & 7 & Agricultural and veterinary sciences & 6.1 & 38 \\
1 & 8 & Civil engineering & 10.2 & 4.4 & 66 \\
1 & 9 & Industrial and information engineering & 13.6 & 7.0 & 64 \\
& & Antiquities, philology, literary studies, art & & & \\
0 & 10 & history & 6.6 & 9.1 & 40 \\
1 & 11 & Psychology & 11.3 & 8.8 & 26 \\
0 & 12 & Law studies & 7.7 & 10.2 & 51 \\
0 & 13 & Economics and statistics & 1.8 & 6.7 & 10 \\
0 & 14 & Political and social sciences & 8.8 & 10.6 & 39 \\
0 & 8 & Architecture & 11.7 & 46 \\
0 & 11 & History, philosophy, pedagogy & 7.5 & 7.5 & 36 \\
\hline
\end{tabular}


Table A19 - The effect of individual characteristics on the likelihood of success (associate professorships).

\begin{tabular}{|c|c|c|c|c|c|c|}
\hline & \multicolumn{3}{|c|}{ Bibliometric } & \multicolumn{3}{|c|}{ Non bibliometric } \\
\hline & Before & $\begin{array}{l}\text { After, } \\
\text { election+ } \\
\text { random } \\
\end{array}$ & $\begin{array}{c}\text { After, pure } \\
\text { randomization }\end{array}$ & Before & $\begin{array}{l}\text { After, election+ } \\
\text { random }\end{array}$ & $\begin{array}{c}\text { After, pure } \\
\text { randomization }\end{array}$ \\
\hline H index & $\begin{array}{c}0.047 * * * \\
(0.010)\end{array}$ & $\begin{array}{l}0.036 * * * \\
(0.011)\end{array}$ & $\begin{array}{l}0.047 * * * \\
(0.015)\end{array}$ & $\begin{array}{l}0.040 * * \\
(0.017)\end{array}$ & $\begin{array}{l}-0.012 \\
(0.011)\end{array}$ & $\begin{array}{c}0.051 * * \\
(0.020)\end{array}$ \\
\hline Insider & $\begin{array}{c}0.346 * * * \\
(0.026)\end{array}$ & $\begin{array}{c}0.289 * * * \\
(0.030)\end{array}$ & $\begin{array}{c}0.161 * * * \\
(0.029)\end{array}$ & $\begin{array}{c}0.395 * * * \\
(0.059)\end{array}$ & $\begin{array}{c}0.409 * * * \\
(0.090)\end{array}$ & $\begin{array}{c}0.281 * * * \\
(0.069)\end{array}$ \\
\hline $\begin{array}{l}\text { commissionerselec } \\
\text { tor from the same } \\
\text { university }\end{array}$ & $\begin{array}{c}0.192 * * * \\
(0.030)\end{array}$ & $\begin{array}{c}0.018 \\
(0.024)\end{array}$ & $\begin{array}{l}0.071 * \\
(0.042)\end{array}$ & $\begin{array}{c}0.292 * * * \\
(0.055)\end{array}$ & $\begin{array}{l}0.173 * \\
(0.093)\end{array}$ & $\begin{array}{c}0.229 * * * \\
(0.065)\end{array}$ \\
\hline $\begin{array}{l}\text { Observations } \\
\text { R-squared } \\
\text { Number of } \\
\text { competitions }\end{array}$ & $\begin{array}{c}2,062 \\
0.144 \\
201\end{array}$ & $\begin{array}{c}1,188 \\
0.132 \\
64\end{array}$ & $\begin{array}{c}1,156 \\
0.072 \\
53\end{array}$ & $\begin{array}{c}557 \\
0.174 \\
72\end{array}$ & $\begin{array}{c}347 \\
0.141 \\
24\end{array}$ & $\begin{array}{c}289 \\
0.151 \\
19\end{array}$ \\
\hline \multicolumn{7}{|c|}{$\begin{array}{l}\text { Heteroscedasticity robust standard errors in parentheses, clustered at competition level, including competition fixed } \\
\text { effects - statistical significance } * * * p<0.01, * * \mathrm{p}<0.05, * \mathrm{p}<0.1 \text {. The equation includes a full set of controls not reported } \\
\text { here. }\end{array}$} \\
\hline & \multicolumn{6}{|c|}{ Table A20 - The effect of individual characteristics on the likelihood of success (full professorships). } \\
\hline & Before & $\begin{array}{l}\text { After, } \\
\text { election+ } \\
\text { random }\end{array}$ & $\begin{array}{c}\text { After, pure } \\
\text { randomization }\end{array}$ & Before & $\begin{array}{l}\text { After, election+ } \\
\text { random }\end{array}$ & $\begin{array}{c}\text { After, pure } \\
\text { randomization }\end{array}$ \\
\hline H index & $\begin{array}{c}0.033 * * \\
(0.016)\end{array}$ & $\begin{array}{l}0.073 * * * \\
(0.017)\end{array}$ & $\begin{array}{l}0.072 * * * \\
(0.017)\end{array}$ & $\begin{array}{c}0.024 \\
(0.031)\end{array}$ & $\begin{array}{l}-0.035 \\
(0.040)\end{array}$ & $\begin{array}{l}-0.002 \\
(0.013)\end{array}$ \\
\hline Insider & $\begin{array}{c}0.383 * * * \\
(0.037)\end{array}$ & $\begin{array}{c}0.366 * * * \\
(0.057)\end{array}$ & $\begin{array}{c}0.314 * * * \\
(0.046)\end{array}$ & $\begin{array}{c}0.520 * * * \\
(0.076)\end{array}$ & $\begin{array}{c}0.485^{* * *} \\
(0.113)\end{array}$ & $\begin{array}{c}0.289 * * * \\
(0.048)\end{array}$ \\
\hline $\begin{array}{l}\text { selector from the } \\
\text { same university }\end{array}$ & $\begin{array}{c}0.147 * * * \\
(0.031)\end{array}$ & $\begin{array}{l}0.099 * \\
(0.052)\end{array}$ & $\begin{array}{c}0.036 \\
(0.038)\end{array}$ & $\begin{array}{l}0.189 * \\
(0.103)\end{array}$ & $\begin{array}{l}-0.081 \\
(0.062)\end{array}$ & $\begin{array}{l}0.151 * \\
(0.084)\end{array}$ \\
\hline Observations & 995 & 541 & 639 & 222 & 85 & 215 \\
\hline R-squared & 0.164 & 0.208 & 0.159 & 0.236 & 0.215 & 0.131 \\
\hline $\begin{array}{l}\text { Number of } \\
\text { competitions }\end{array}$ & 100 & 38 & 32 & 38 & 6 & 16 \\
\hline
\end{tabular}

Heteroscedasticity robust standard errors in parentheses, clustered at competition level, including competition fixed effects - statistical significance $* * * \mathrm{p}<0.01$, ** $\mathrm{p}<0.05, * \mathrm{p}<0.1$. The equation includes a full set of controls not reported here. 
Table A21 - Number of competitions by research area in our sample (Padua, Milan - 'Statale', Naples 'Federico II' and Rome - 'La Sapienza') and in the whole Italian academia - associate professor competitions.

\begin{tabular}{cclcccc}
\hline \multirow{2}{*}{ bibliometric } & $\begin{array}{c}\text { research area } \\
(\text { areaCUN) }\end{array}$ & \multicolumn{2}{c}{ Sample } & \multicolumn{3}{c}{ all universities } \\
& \multicolumn{1}{c}{ research area } & $\mathrm{N}$ & $\%$ & $\mathrm{~N}$ & $\%$ \\
\hline 1 & 1 & Mathematics and informatics & 31 & 7.1 & 174 & 4.6 \\
1 & 2 & Physics & 22 & 5.1 & 137 & 3.6 \\
1 & 3 & Chemistry & 32 & 7.4 & 150 & 3.9 \\
1 & 4 & Earth sciences & 18 & 4.2 & 58 & 1.5 \\
1 & 5 & Biology & 42 & 9.7 & 254 & 6.7 \\
1 & 6 & Medicine & 102 & 23.5 & 625 & 16.4 \\
1 & 7 & Agricultural and veterinary sciences & 36 & 8.3 & 201 & 5.3 \\
1 & 8 & Civil engineering & 4 & 0.9 & 98 & 2.6 \\
1 & 9 & Industrial and information engineering & 24 & 5.5 & 331 & 8.7 \\
0 & 10 & Antiquities, philology, literary studies, art & 25 & 5.8 & 339 & 8.9 \\
1 & 11 & history & 8 & 1.8 & 88 & 2.3 \\
0 & 12 & Psychology & 26 & 6 & 400 & 10.5 \\
0 & 13 & Economics and statistics & 17 & 3.9 & 407 & 10.7 \\
0 & 14 & Political and social sciences & 14 & 3.2 & 125 \\
0 & 8 & Architecture & 12 & 2.8 & 147 & 3.3 \\
0 & 11 & History, philosophy, pedagogy & 21 & 4.8 & 281 & 7.4 \\
\hline
\end{tabular}

Table A22 - Number of competitions by research area in our sample (Padua, Milan - 'Statale', Naples 'Federico II' and Rome - 'La Sapienza') and in the whole Italian academia - full professor competitions.

\begin{tabular}{|c|c|c|c|c|c|c|}
\hline \multirow{2}{*}{ bibliometric } & \multirow{2}{*}{$\begin{array}{c}\text { research } \\
\text { area } \\
(\text { areaCUN) }\end{array}$} & \multirow{2}{*}{ research area } & \multicolumn{2}{|c|}{ Sample } & \multicolumn{2}{|c|}{ all universities } \\
\hline & & & $\mathrm{N}$ & $\%$ & $\mathrm{~N}$ & $\%$ \\
\hline 1 & 1 & Mathematics and informatics & 11 & 4.8 & 95 & 3.9 \\
\hline 1 & 2 & Physics & 6 & 2.6 & 75 & 3.1 \\
\hline 1 & 3 & Chemistry & 19 & 8.3 & 98 & 4.0 \\
\hline 1 & 4 & Earth sciences & 6 & 2.6 & 44 & 1.8 \\
\hline 1 & 5 & Biology & 23 & 10 & 152 & 6.2 \\
\hline 1 & 6 & Medicine & 58 & 25.2 & 365 & 14.8 \\
\hline 1 & 7 & Agricultural and veterinary sciences & 19 & 8.3 & 114 & 4.6 \\
\hline 1 & 8 & Civil engineering & 5 & 2.2 & 54 & 2.2 \\
\hline 1 & 9 & Industrial and information engineering & 15 & 6.5 & 215 & 8.7 \\
\hline 0 & 10 & $\begin{array}{l}\text { Antiquities, philology, literary studies, } \\
\text { art history }\end{array}$ & 13 & 5.7 & 223 & 9.1 \\
\hline 1 & 11 & Psychology & 8 & 3.5 & 69 & 2.8 \\
\hline 0 & 12 & Law studies & 16 & 7 & 288 & 11.7 \\
\hline 0 & 13 & Economics and statistics & 6 & 2.6 & 274 & 11.1 \\
\hline 0 & 14 & Political and social sciences & 7 & 3 & 80 & 3.3 \\
\hline 0 & 8 & Architecture & 9 & 3.9 & 90 & 3.7 \\
\hline \multirow[t]{2}{*}{0} & 11 & History, philosophy, pedagogy & 9 & 3.9 & 226 & 9.2 \\
\hline & & Total & 230 & & 2462 & \\
\hline
\end{tabular}


Table A23 - Number of competitions and number of applications per competition (associate professors).

\begin{tabular}{|c|c|c|c|c|c|c|c|}
\hline \multirow[b]{2}{*}{ Reform } & \multirow[b]{2}{*}{ year } & \multicolumn{3}{|c|}{ number of competitions } & \multicolumn{3}{|c|}{ average applicants per competition } \\
\hline & & Italy & $\begin{array}{c}4 \\
\text { universities }\end{array}$ & our sample & Italy & $\begin{array}{c}4 \\
\text { universities }\end{array}$ & our sample \\
\hline \multirow{5}{*}{ before } & 2003 & 515 & 72 & 61 & 6.9 & 7.0 & 8.3 \\
\hline & 2004 & 792 & 68 & 54 & 8.5 & 8.3 & 8.8 \\
\hline & 2005 & 1048 & 149 & 135 & 10.2 & 10.9 & 11.3 \\
\hline & 2006 & 244 & 23 & 23 & 4.7 & 4.9 & 5.0 \\
\hline & 2007 & 4 & - & - & 5.0 & - & - \\
\hline \multirow[t]{2}{*}{ after } & 2008 & 1213 & 162 & 161 & 14.2 & 18.7 & 18.7 \\
\hline & Total & 3816 & 474 & 434 & 10.3 & 12.3 & 13.0 \\
\hline
\end{tabular}

Table A24 - Number of competitions and number of applications per competition (full professors). number of competitions average applicants per competition

\begin{tabular}{|c|c|c|c|c|c|c|c|}
\hline Reform & year & Italy & 4 universities & our sample & Italy & 4 universities & our sample \\
\hline \multirow{5}{*}{ before } & 2003 & 330 & 34 & 30 & 6.9 & 6.7 & 6.6 \\
\hline & 2004 & 530 & 29 & 21 & 8.1 & 7.2 & 7.3 \\
\hline & 2005 & 667 & 69 & 69 & 10.1 & 11.0 & 11.4 \\
\hline & 2006 & 193 & 18 & 18 & 3.8 & 4.6 & 4.6 \\
\hline & 2007 & 4 & & & 3.5 & & \\
\hline \multirow[t]{2}{*}{ after } & 2008 & 738 & 92 & 92 & 14.6 & 15.9 & 16.1 \\
\hline & Total & 2462 & 242 & 230 & 10.1 & 11.3 & 11.7 \\
\hline
\end{tabular}


Table A25 - Fixed effect linear probability model for the probability of obtaining the chair at the department opening the position for associate professorship, years 2003 to 2008, University of Padua, Milan - Statale, Rome - La Sapienza, Naples - Federico II.

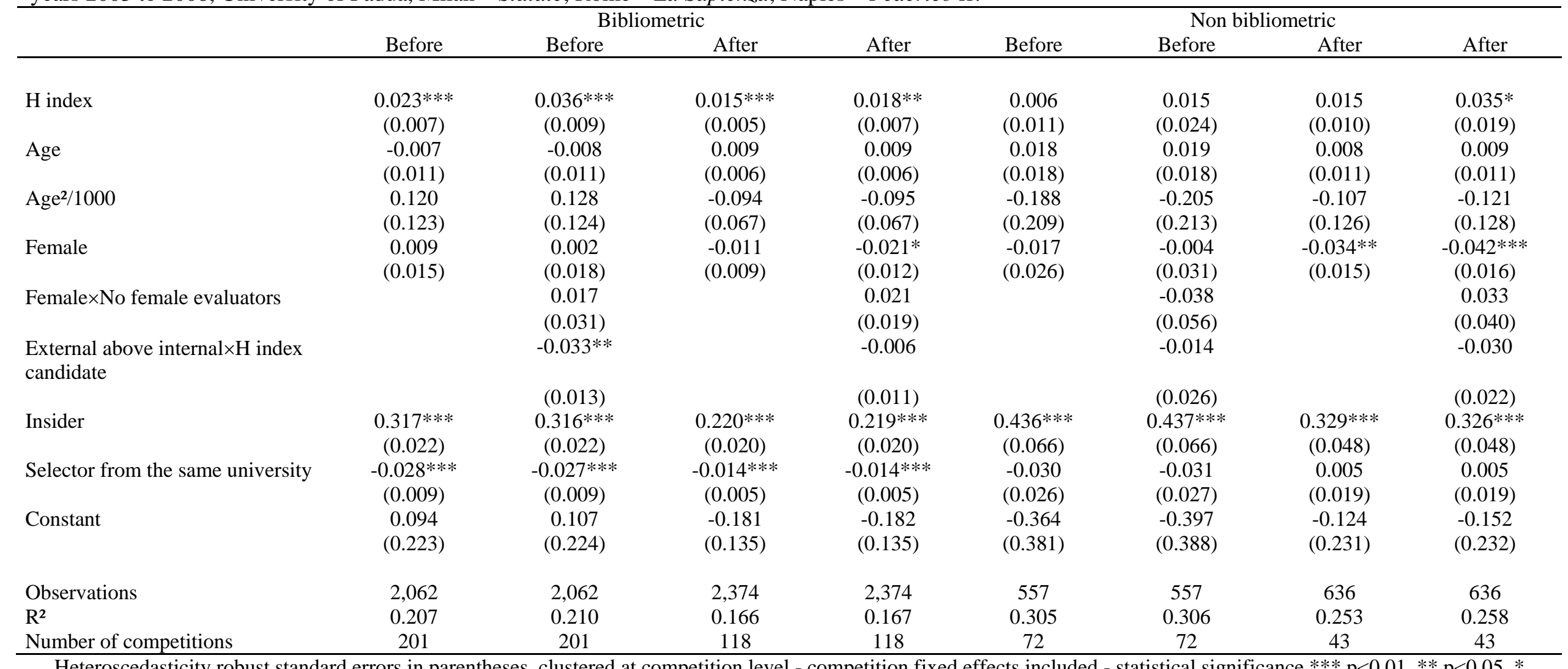

Heteroscedasticity robust standard errors in parentheses, clustered at competition level - competition fixed effects included - statistical significance $* * * \mathrm{p}<0.01, * * \mathrm{p}<0.05, *$ $\mathrm{p}<0.1$ 
Table A26 - Fixed effect linear probability model for the probability of obtaining a chair at a department different from the one opening the position for associate professorship, years 2003 to 2008, University of Padua, Milan - Statale, Rome - La Sapienza, Naples - Federico II.

\begin{tabular}{|c|c|c|c|c|c|c|c|c|}
\hline & \multicolumn{4}{|c|}{ Bibliometric } & \multicolumn{4}{|c|}{ Non bibliometric } \\
\hline & Before & Before & After & After & Before & Before & After & After \\
\hline \multirow[t]{2}{*}{$\mathrm{H}$ index } & $0.029 * * *$ & $0.028 * *$ & $0.030 * * *$ & $0.031 * * *$ & $0.037 * *$ & 0.026 & 0.002 & 0.000 \\
\hline & $(0.009)$ & $(0.011)$ & $(0.007)$ & $(0.009)$ & $(0.015)$ & $(0.034)$ & $(0.009)$ & $(0.019)$ \\
\hline \multirow[t]{2}{*}{ Age } & -0.017 & -0.017 & 0.001 & 0.001 & -0.026 & -0.031 & 0.002 & 0.001 \\
\hline & $(0.014)$ & $(0.014)$ & $(0.007)$ & $(0.007)$ & (0.019) & $(0.019)$ & $(0.016)$ & $(0.016)$ \\
\hline \multirow[t]{2}{*}{$\mathrm{Age}^{2 / 1000}$} & 0.185 & 0.185 & -0.009 & -0.008 & 0.270 & 0.318 & -0.009 & 0.000 \\
\hline & $(0.157)$ & $(0.157)$ & $(0.081)$ & $(0.082)$ & $(0.209)$ & $(0.214)$ & $(0.177)$ & $(0.178)$ \\
\hline \multirow[t]{2}{*}{ Female } & -0.004 & -0.002 & 0.000 & 0.003 & -0.046 & $-0.086^{* *}$ & 0.008 & 0.023 \\
\hline & $(0.017)$ & $(0.020)$ & $(0.011)$ & $(0.014)$ & $(0.031)$ & $(0.035)$ & $(0.023)$ & $(0.028)$ \\
\hline \multirow[t]{2}{*}{ Female $\times$ No female evaluators } & & -0.006 & & -0.005 & & $0.118^{*}$ & & -0.062 \\
\hline & & $(0.036)$ & & $(0.022)$ & & $(0.060)$ & & $(0.046)$ \\
\hline \multirow{2}{*}{$\begin{array}{l}\text { External above internal } \times \mathrm{H} \text { index } \\
\text { candidate }\end{array}$} & & 0.003 & & -0.002 & & 0.016 & & 0.001 \\
\hline & & $(0.018)$ & & $(0.014)$ & & $(0.037)$ & & $(0.022)$ \\
\hline \multirow[t]{2}{*}{ Insider } & $0.082 * * *$ & $0.082 * * *$ & 0.016 & 0.016 & 0.019 & 0.016 & 0.038 & 0.039 \\
\hline & $(0.023)$ & $(0.023)$ & $(0.015)$ & $(0.015)$ & $(0.045)$ & $(0.045)$ & $(0.046)$ & $(0.046)$ \\
\hline \multirow[t]{2}{*}{ Selector from the same university } & $0.220 * * *$ & $0.219 * * *$ & $0.050 * *$ & $0.050 * *$ & $0.332 * * *$ & $0.339 * * *$ & $0.191 * * *$ & $0.193 * * *$ \\
\hline & $(0.030)$ & $(0.030)$ & $(0.022)$ & $(0.022)$ & $(0.057)$ & $(0.056)$ & $(0.059)$ & $(0.058)$ \\
\hline \multirow[t]{2}{*}{ Constant } & 0.433 & 0.433 & 0.014 & 0.016 & $0.709^{*}$ & $0.805^{*}$ & -0.010 & 0.010 \\
\hline & $(0.297)$ & $(0.297)$ & $(0.163)$ & $(0.165)$ & $(0.420)$ & $(0.426)$ & $(0.334)$ & $(0.336)$ \\
\hline Observations & 1,871 & 1,871 & 2,265 & 2,265 & 490 & 490 & 600 & 600 \\
\hline $\mathrm{R}^{2}$ & 0.066 & 0.067 & 0.016 & 0.017 & 0.130 & 0.137 & 0.042 & 0.045 \\
\hline Number of competitions & 200 & 200 & 118 & 118 & 67 & 67 & 43 & 43 \\
\hline
\end{tabular}

Heteroscedasticity robust standard errors in parentheses, clustered at competition level - competition fixed effects included - statistical significance $* * *$ p $<0.01, * * p<0.05$, $*$ $\mathrm{p}<0.1$ 
Table A27 - Fixed effect linear probability model for the probability of obtaining the chair at the department opening the position for full professorship, years 2003 to 2008, University of Padua, Milan - Statale, Rome - La Sapienza, Naples - Federico II.

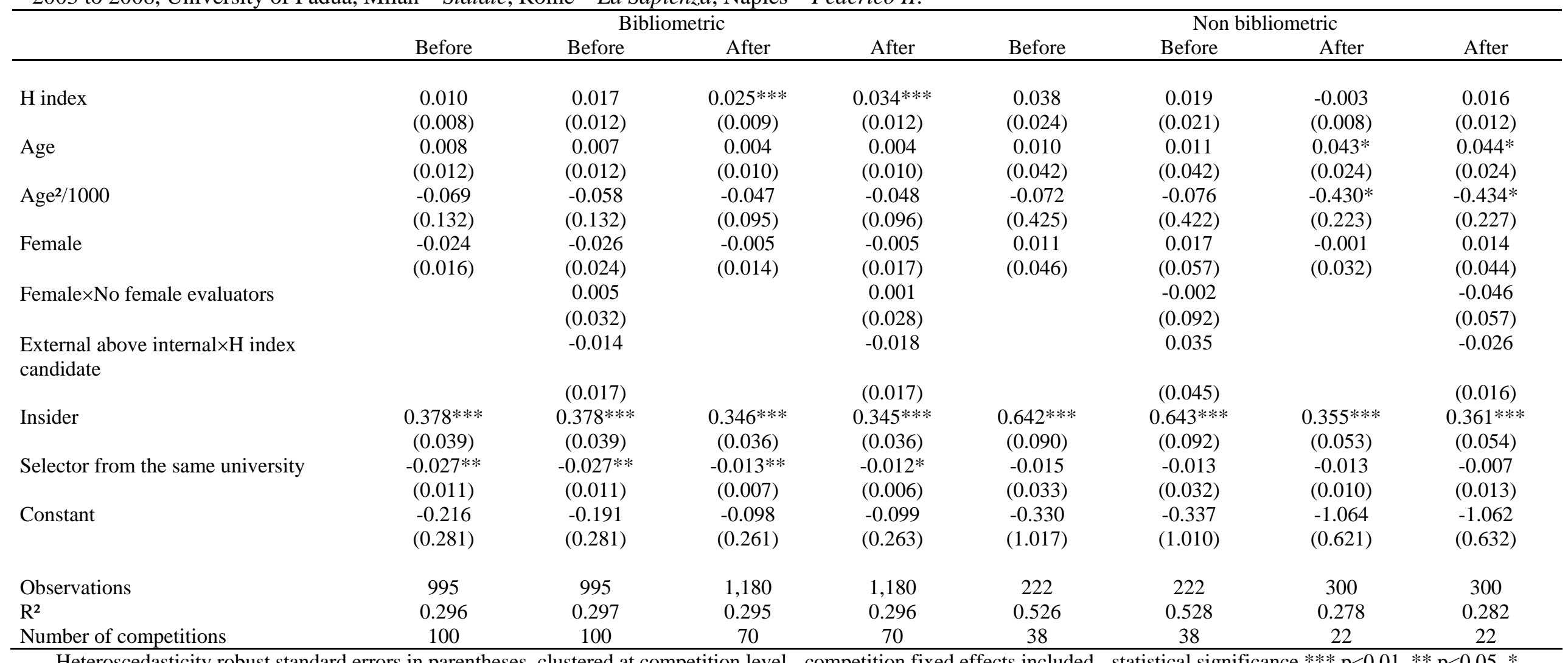

Heteroscedasticity robust standard errors in parentheses, clustered at competition level - competition fixed effects included - statistical significance $* * * \mathrm{p}<0.01, * * \mathrm{p}<0.05, *$ 
Table A28 - Fixed effect linear probability model for the probability of obtaining a chair at a department other than the one opening the position for full professorship, years 2003 to 2008, University of Padua, Milan - Statale, Rome - La Sapienza, Naples - Federico II.

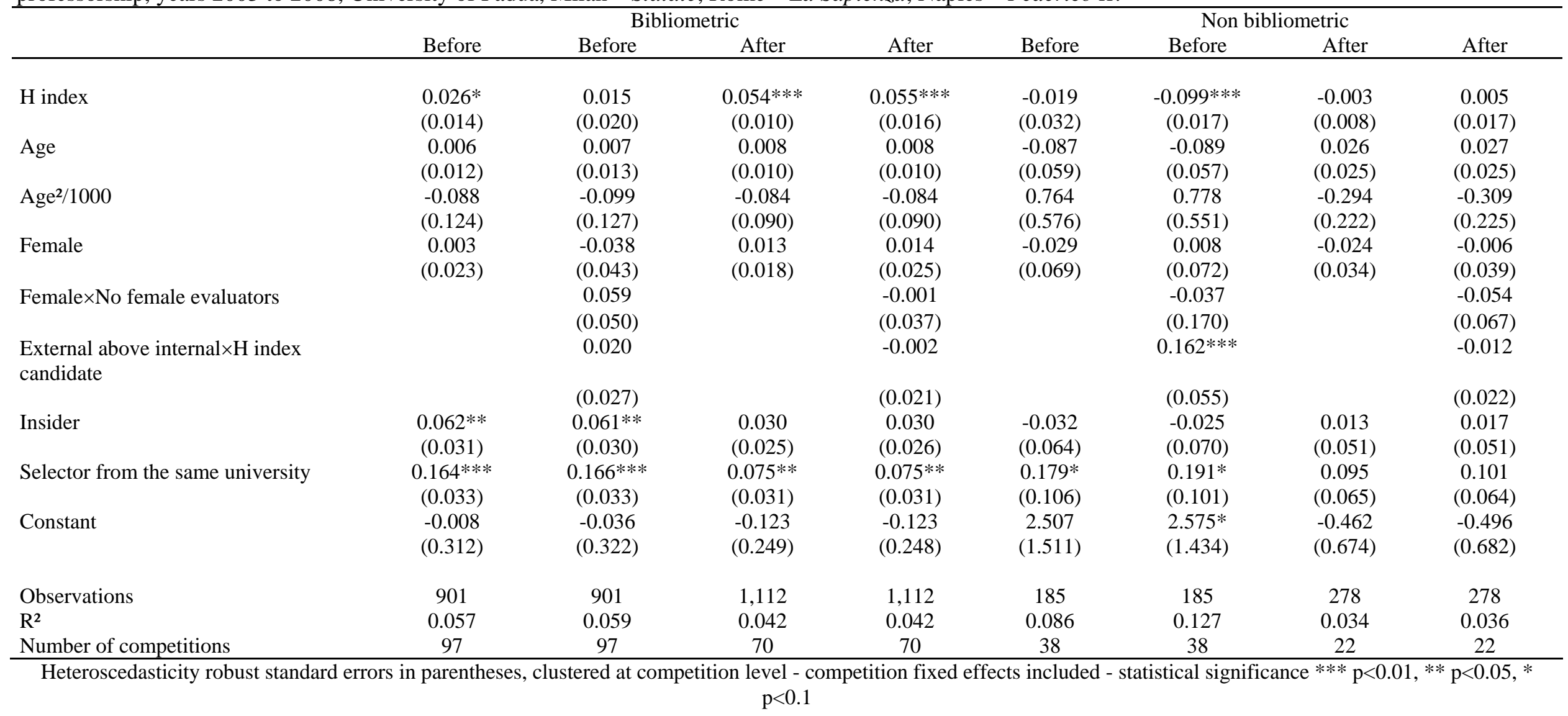

